Illinois State University

ISU ReD: Research and eData

Theses and Dissertations

7-2-2019

\title{
Suicide Literacy and Laypersons' Ability to Accurately Recognize Suicide Warning Signs and Risk Factors
}

Salman Ibrahim

Illinois State University, smbrahim@memphis.edu

Follow this and additional works at: https://ir.library.illinoisstate.edu/etd

Part of the Clinical Psychology Commons

\section{Recommended Citation}

Ibrahim, Salman, "Suicide Literacy and Laypersons' Ability to Accurately Recognize Suicide Warning Signs and Risk Factors" (2019). Theses and Dissertations. 1153.

https://ir.library.illinoisstate.edu/etd/1153

This Thesis is brought to you for free and open access by ISU ReD: Research and eData. It has been accepted for inclusion in Theses and Dissertations by an authorized administrator of ISU ReD: Research and eData. For more information, please contact ISUReD@ilstu.edu. 


\section{SUICIDE LITERACY AND LAYPERSONS' ABILITY TO ACCURATELY RECOGNIZE SUICIDE WARNING SIGNS AND RISK FACTORS}

\section{SALMAN IBRAHIM}

70 Pages

Suicide is considered a public health crisis in the United States due to the large number of individuals attempting and completing suicide each year. Oftentimes, the first line of defense or "gatekeepers" against suicide is non-mental health professionals. The body of literature on suicide risk assessment has not explored the efficacy of non-mental health professionals' ability to accurately recognize various levels of suicide risk. This study focused on examining whether non-mental health professionals' ability to accurately recognize suicide risk in others is influenced by their level of suicide literacy (knowledge regarding the various aspects of suicide). This study also examined whether accuracy in assessment of suicide risk varies based on the demographic factors of sexual orientation and gender identity. Accuracy determining suicide risk was gauged using four expertly validated vignettes that each demonstrated a specific level of suicide risk (high, moderate, low, or none). Suicide literacy was gauged using the Literacy of Suicide Scale, which is a validated 26-item scale that asks participants to answer "true", "false", or "I don't know" to an item regarding some aspect of suicide. This study required all 289 participants to complete the vignettes and the Literacy of Suicide Scale. It was hypothesized that participants with increased levels of suicide literacy would be more accurate at recognizing suicide risk and participants belonging to the LGBTQ community would be more accurate at recognizing suicide risk than non-LGBTQ participants. Results of this study demonstrated that 
there was a significant relationship between participants ability to accurately recognize suicide risk and increased levels of suicide literacy with regards to the "high risk" vignette but not with the other vignettes. The results also demonstrated that there was no significant different LGBTQ participants and non-LGBTQ participants ability to accurately recognize suicide risk. Due to the scant research in this area, further research is required but the findings of this study could inform future research and eventually, suicide prevention efforts to help combat this public health crisis. KEYWORDS: suicide literacy; suicide risk assessment; suicide risk factors; suicide warning signs. 


\title{
SUICIDE LITERACY AND LAYPERSONS' ABILITY TO ACCURATELY RECOGNIZE SUICIDE WARNING SIGNS AND RISK FACTORS
}

\author{
SALMAN IBRAHIM
}

\author{
A Thesis Submitted in Partial \\ Fulfillment of the Requirements \\ for the Degree of \\ MASTER OF SCIENCE \\ Department of Psychology \\ ILLINOIS STATE UNIVERISTY
}


(C) 2019 Salman Ibrahim 


\title{
SUICIDE LITERACY AND LAYPERSONS' ABILITY TO ACCURATELY RECOGNIZE SUICIDE WARNING SIGNS AND RISK FACTORS
}

\author{
SALMAN IBRAHIM
}

COMMITTEE MEMBERS:

Leandra Parris, Chair

Daniel Lannin 


\section{CONTENTS}

Page

CONTENTS

TABLES

FIGURES

CHAPTER I: STATEMENT OF THE PROBLEM 1

CHAPTER II: LITERATURE REVIEW

Theories of Suicide $\quad 5$

$\begin{array}{ll}\text { Psychodynamic Theory of Suicide } & 6\end{array}$

$\begin{array}{ll}\text { Biological Theories of Suicide } & 7\end{array}$

The Interpersonal-Psychological Theory of Suicide 8

Assessing Suicidality 11

$\begin{array}{ll}\text { Warning Signs } & 11\end{array}$

$\begin{array}{ll}\text { Suicide Myths } & 12\end{array}$

$\begin{array}{ll}\text { Risk Factors } & 13\end{array}$

$\begin{array}{ll}\text { Mental Disorders } & 14\end{array}$

$\begin{array}{ll}\text { Family Conflict } & 14\end{array}$

$\begin{array}{ll}\text { Past Suicide Attempts } & 15\end{array}$

$\begin{array}{ll}\text { Social Isolation } & 16\end{array}$

$\begin{array}{ll}\text { Physical Illness } & 16\end{array}$

$\begin{array}{ll}\text { Demographic Factors } & 17\end{array}$

$\begin{array}{ll}\text { Social Support } & 17\end{array}$

$\begin{array}{ll}\text { Varying Levels of Suicide Risk } & 18\end{array}$ 
Mental Health Literacy

Suicide Literacy

Current Study

CHAPTER III: METHOD

Participants

Instruments

Demographic Survey

Suicide Risk Vignettes

Literacy of Suicide Scale

Procedure

Data Analysis

CHAPTER IV: RESULTS

Correlations

Research Question 1

Research Question 2

Exploratory Analyses: Suicide Literacy

General Findings: Accurate Recognition of Suicide Risk

Additional Findings

CHAPTER V: DISCUSSION

Limitations and Future Research

Implications 
APPENDIX B: SUICIDE RISK VIGNETTES

APPENDIX C: LITERACY OF SUICIDE SCALE 


\section{TABLES}

Table

Page

$\begin{array}{ll}\text { 1. Exposure to Suicide } & 27\end{array}$

2. Correlations $\quad 34$

3. Suicide Risk Assessment Accuracy Comparison Across Sexual Orientations 34

4. Suicide Risk Assessment Accuracy Comparison Across Gender Identities 36

5. Literacy of Suicide Scale (LOSS) Correct Responses 37

6. Suicide Literacy Comparison Across Sexual Orientations 40

7. Suicide Literacy Comparison Across Gender Identities 41

8. Suicide Risk Vignettes Correct Responses $\quad 42$ 


\section{FIGURES}

Figure $\quad$ Page

1. Suicide risk matrix ranging from low risk, medium risk, and higher risk. 26 


\section{CHAPTER I: STATEMENT OF THE PROBLEM}

Suicide is a national and global public health crisis. According to the World Health Organization (WHO), approximately 800,000 individuals around the world die by suicide each year (World Health Organization, 2013). Suicide is defined as self-inflicted harm with the intent to die that results in death, while a suicide attempt is defined as self-inflicted harm to oneself that does not result in death (Van Orden et. al., 2010). According to a recent report by the Center for Disease Control (2018), suicide is now the $10^{\text {th }}$ leading-cause of death for Americans, totaling about 45,000 suicides per year. For every suicide there are approximately ten non-fatal attempts (Centers for Disease Control \& Prevention [CDC], 2018). Alarmingly, suicide is now the second leading-cause of death among youth in the US, passing even homicide (Centers for Disease Control \& Prevention [CDC], 2018). It is commonly held that more individuals struggle with suicidal ideation, otherwise known as thoughts of suicide, than those that go on to attempt or complete suicide.

Suicide risk differs significantly across demographics. For example, men are three times as likely to die by suicide as women are and suicide rates are highest among American Indians and Alaska Natives and lowest among black people (Centers for Disease Control \&Prevention [CDC], 2018). It is important to note that while men complete suicide at a significantly higher rate, women attempt suicide at a far higher rate. Based on the aforementioned statistics it is apparent that hundreds of thousands of individuals are affected by suicide a year but it is unknown why so many individuals attempt or complete suicide in the first place.

Suicidal ideation is often the initial focus of inquiry for mental health professionals seeking to assess suicide risk (Silverman \& Berman, 2014). While individuals who are experiencing suicidal ideation and are at a risk of suicide may not always respond truthfully to 
questions aimed at assessing suicidal ideation (Busch, Fawcett, \& Jacobs, 2003), it remains the primary starting point for mental health professionals because simple behavioral observations are insufficient to gauge suicide risk (Silverman \& Berman, 2014). Suicide risk assessment is an inherently collaborative process. The suicide risk assessment relies heavily on the suicidal individual honestly disclosing their suicidal ideation and the mental health professional gauging factors such as level of risk, intent, plan, and potential means for completing suicide (Bryan \& Rudd, 2006). While there exists a significant body of literature examining how mental health professionals assess suicide risk, there is little research available on how well the general population can recognize the varying levels of suicidal ideation in others. This lack of research on how well the general population can recognize suicidal risk has significant real-world repercussions.

Past research has shown that $50 \%-70 \%$ of individuals contemplating suicide talked to family or friends about their suicidal thoughts, making them the first line of defense against suicide (Coombs et al., 1992; Robins, Gassner, Kayes, Wilkinson, \& Murphy, 1959). While there exists an emphasis on mental health professionals becoming competent assessors of suicidal risk, there is less emphasis placed on training the general public to recognize suicidal risk, even though those at risk for suicide are likely to reach out to their family and friends about their suicidal ideation. If the "first line of defense" is ineffective at recognizing suicide risk, individuals who could have been referred to the proper treatment go without. One potential way to improve accurate recognition of suicide risk among the general public is to increase mental health literacy, specifically surrounding suicide.

Mental health literacy is defined as the knowledge that one possesses regarding mental disorders (Jorm et al., 2006). Low levels of mental health literacy has been identified as a factor 
that prevents suicidal individuals from seeking appropriate help (Jorm et al., 2006). Suicide literacy, which is a specific type of mental health literacy, is defined as an understanding of the following facets of suicidality: Warning signs/symptoms, causes of suicidality, risk factors, and proper treatment and prevention (Batterham et al., 2013). Researchers have demonstrated that lower levels of suicide literacy may be linked to lower likelihood of accurately recognizing suicidal ideation (Batterham et al., 2013). Thus, it stands to reason that if an individual's suicide literacy was increased, they would be more likely to accurately recognize suicide risk in others. In other words, increasing an individual's knowledge regarding warning signs, causes of suicidality, risk factors, and other facets of suicidality may increase their ability to recognize various levels of suicide risk. While suicide literacy has yet to be adequately researched, the research on mental health literacy showed that those with higher levels of mental health literacy demonstrated significant positive outcomes in help-seeking behavior (Jorm, 2012). As it was previously established, a significant portion of suicidal individuals reach out to family and friends (who are unlikely to be mental health professionals) to discuss their suicidality, making it imperative that the general public (i.e. non-mental health professionals) possess a sufficient level of suicide literacy.

The aim of this study is to assess how well the average layperson (i.e. non-mental health professional) can recognize suicide risk by applying their suicide literacy to expertly validated vignettes that detail varied in levels of suicidal risk. Participants were presented with four expertly validated vignettes and asked to assess whether the level of suicidal risk is nonexistent, low, moderate, or high. The vignettes used in this study attempt to closely mimic real-world scenarios. Participants were also tasked with completing a suicide literacy scale in order to examine the relationship between level of suicide literacy and the ability to accurately recognize 
suicide risk. If a link is definitively established between high levels of suicide literacy and increased ability to recognize suicidal risk, it could inform suicide prevention efforts of the importance of suicide literacy. 


\section{CHAPTER II: LITERATURE REVIEW}

Research on suicidality is an area of research that has been extensively researched for

decades. Historically, most of the literature on suicide has focused on attempting to unravel why individuals choose suicide. Many theories have emerged that attempt to explain all suicidal behavior or specific facets of suicide. This literature review will cover theories that attempt to explain suicidal behavior including psychodynamic theories, biological theories, and the interpersonal-psychological theory of suicide. In recent years, there has been a shift from attempting to figure out why people choose suicide, to focusing on prevention efforts. This literature review will examine theory-driven suicide prevention research by focusing on various transtheoretical warning signs, suicide risk factors, and suicide literacy in general. Particular consideration will be given to factors of interest like social support and demographic characteristics.

\section{Theories of Suicide}

Before discussing the specifics of the current study, it is important to examine the various theories of suicide that exists in the body of literature on the topic. A firm understanding of the theories of suicide is important because they inform clinical practice with suicidal individuals. For example, if the majority of the theories of suicide posit that hopelessness is the root cause of suicidal ideation, mental health professionals seeking to treat suicidal individuals may choose to focus on hopelessness as the presenting problem. Theories of suicide also guide the direction of future research. Using the previous example of hopelessness, researchers may decide to focus their line of inquiry on hopelessness if multiple theories of suicide point to it as the root cause of suicidal ideation. 
Prominent theories of suicidology include the interpersonal-psychological theory of suicide, biological theories, and psychodynamic theories (Eaddy et al., 2018). The interpersonal theory of suicide states that the existence of both thwarted belongingness and perceived burdensomeness can explain suicide. The biological theories primarily focus on a combination of psychological stressors and an existing genetic susceptibility to suicide as the components of suicidal behavior. Psychodynamic theories, being so varied, state that suicide can be caused by attempting to escape from psychological/emotional pain, unconscious drives, or dysfunctional attachment. These differing theories are not necessarily in conflict with one another but rather, they attempt to explain a specific part of suicidal etiology/behavior. That being said, it is highly likely that those that die by suicide present multiple risk factors from each theoretical perspective.

\section{Psychodynamic Theory of Suicide}

While the psychodynamic viewpoint is an exceedingly broad and diverse one, the majority of prominent psychodynamic theorists postulate that suicide is an inherently aggressive act (Lees \&Stimpson, 2002). Psychodynamic theorists therefore argue that in order to understand suicidal behavior, a firm grasp of the aggressive instincts of the human psyche is required. In his well-known work "Mourning and Melancholia" (Freud, 1917), Freud argued that suicidal behavior is an internalization of murderous intentions that an individual holds for another person. Freud's original theory posits that for suicide to occur an individual must also be able to view themselves from a detached perspective, or in psychodynamic terminology, as an "object". According to Freud (1917, p. 252), an individual can only complete suicide if they view their own ego as a distinct and separate "object." As Freud's views developed, he also argued that suicide could be viewed as acting out, often unknown to the individual, as a result of an 
unresolved childhood trauma. Thus, Freud argued that in order for an individual to complete suicide they must first have an aggressive wish towards an object (a person in the individual's life), coupled with an ability to view themselves as a distinct object, followed by the desire to act out which is more often than not precipitated by an unresolved childhood trauma. Freud's early ideas on suicide helped lay the groundwork for psychodynamic theorists aiming to explain suicidal behavior but it is important to note that the majority of psychodynamic theories on suicide were proposed and built-upon by those that came after.

Karl Menninger's seminal theory of suicide (1938) included three motives as explaining suicidal behavior. First, an individual's desire to kill another person which first manifests as a desire to harm an external individual but is later internalized into one's own ego. Second is the desire to be killed. Menninger argues that the desire to be killed is a guilt-driven reaction to the first motive. According to this theory, once an individual is enmeshed in feelings of guilt, they also begin to believe that they deserve to be punished. Third is the desire to die which manifests as a form of depression. Menninger differentiates this motive from the second motive (the desire to be killed) by emphasizing that the desire to die is rooted in the want to escape pain rather than being rooted in guilt like the desire to be killed. Menninger argued that all of these motives must be present for an individual to die by suicide. Freud's earlier work on suicide laid the groundwork for Menninger who built upon his work by focusing heavily on excessive guilt as a primary motive for suicide. It is important to note that while psychodynamic theories were a vital foundation for later researchers, they have received little-to-no empirical support.

\section{Biological Theories of Suicide}

The stress-diathesis model is a biological theory commonly used to explain suicidal behavior. The stress-diathesis model proposes that certain individuals are genetically predisposed 
to suicidal behavior and stressors in their lives push them to act on that predisposition. A predisposition, otherwise known as a diathesis, to suicidal behavior can manifest in multiple forms such as personality traits (impulsivity, aggression, pessimism etc.) or a history of trauma or family history of suicide. Stressors that can precipitate suicidal behavior in those that have the aforementioned predisposition/diathesis include interpersonal or environmental stressors, medical illnesses, and psychiatric conditions. The stress-diathesis model argues that in order for someone to attempt/complete suicide, both a predisposition/diathesis and a stressor must be present.

Biological theories also argue that a relationship exists between mental illness and suicidal behavior. Past research has shown that $90 \%$ of those who have completed suicide have a diagnosed mental illness (Hawton \& Van Heeringen, 2009). Among populations with mental illness diagnoses, those diagnosed with mood disorders make up $30 \%$ to $60 \%$ of the aforementioned statistic. Studies focused on neuropsychology have shown increasing evidence for biological theories of suicidal behavior, but the inherent difficulties associated with researching the biology or brain chemistry of a varied and complex behavior like suicide have caused strictly biological theories of suicide to fall out of favor in the current literature.

\section{The Interpersonal-Psychological Theory of Suicide}

Thomas Joiner (2005), one of the world's leading experts on suicide, developed the interpersonal-psychological theory of suicidal behavior in 2005. The Interpersonal-Psychological Theory of Suicide (IPTS) argues that an individual will not die by suicide unless two psychological components are present: "Thwarted belongingness" and "perceived burdensomeness" (Joiner \&Van Orden, 2008, p. 80). In addition to thwarted belongingness and perceived burdensomeness, an individual must also possess acquired capability, which refers to 
the ability to overcome the natural fear of death that is inherent in human beings. These components are often divided into two categories: desire for suicide (thwarted belongingness and perceived burdensomeness) and acquired capability (Joiner, 2005).

Thwarted belongingness refers to a sense of alienation from others in a familial, social, or other important setting. As many theorists have stated over the years, a sense of belongingness is integral to psychological well-being. For example, in his theory on psychache Edwin Shneidman (1993), argued that significant alienation can cause a person to experience unbearable pain.

According to Schneidman, it is the desire to stop the unbearable pain that causes an individual to attempt suicide (Shneidman, 1993). There is an abundance of evidence that shows that thwarted belongingness plays a key role in suicidal behavior (Van Orden et al., 2008). Research has also shown that there is a decline in suicide rates during holiday seasons (when people come together with family and friends to celebrate) and a similar decline during times of personal/societal tragedy (when people come together with family and friends to grieve), further lending strength to the argument that thwarted belongingness is a precipitating factor in suicidal behavior (Van Orden et al., 2008). Both of the aforementioned instances encourage social connectedness, decreasing the likelihood of individuals experiencing thwarted belongingness. Research has found a similar effect in instances that promote group belongingness like the success of a sports team or national tragedies, such as the $9 / 11$ terrorist attacks. Many studies have illustrated this relationship between suicidal behavior and thwarted belongingness across many populations. For example, a study done by Van Orden, Witt, Bender, and Joiner found that college students' suicidal ideation/behavior peaked during the summer semester (Van Orden et al., 2008). They also found that the low belongingness associated with the summer semester (when the majority 
of students are not on campus) played a key role in the association between suicidality and semester (Van Orden et al., 2008).

In addition to thwarted belongingness, IPTS states that perceived burdensomeness is also a precipitating factor in suicidal ideation/behavior. Perceived burdensomeness refers to the skewed perspective that one is a burden on friends, family, society, or any combination of these (Joiner, 2005). An individual high in perceived burdensomeness believes that their suicide will free friends, family, and/or society from having to care for them physically, financially, or emotionally. This belief causes individuals high in perceived burdensomeness to genuinely believe that their family members, friends, and society would be better off if they ended their lives. In a study looking at suicide notes researchers found the presence of language expressing some form of perceived burdensomeness (Joiner et al., 2002). Researchers also found significantly more expressions of burdensomeness in the suicide notes of those who used particularly lethal methods (firearms) than those who used less lethal methods (overdose) (Joiner et al., 2002). This may indicate that higher levels burdensomeness are significantly more dangerous than lower levels of burdensomeness in those that attempt suicide due to the difference in the means utilized. Many similar studies have added evidence to IPTS' claim that perceived burdensomeness plays a significant role in suicidal ideation/behavior. In the last decade, Joiner's IPTS has become an exceedingly popular theory of suicide due to its robust empirical backing. Due to its emphasis on social connectedness (or lack thereof) IPTS is particularly relevant to the current study. It is important to note that, with a few exceptions, the history of research on suicidality has been largely atheoretical (Van Orden et. al., 2010). Instead, the bulk of suicide research has focused on warning signs, risk factors, and suicide prevention strategies. 


\section{Assessing Suicidality}

Unlike with many physical illnesses, there exists no simple test that could be run in order to detect suicidality. Nonetheless, it is imperative that mental health professionals thoroughly assess suicidality or individuals could suffer potentially lethal consequences. While it is important that mental health professionals are adept at assessing suicide risk, it may be just as important (if not more important) that non-mental health professionals are also capable of recognizing suicide risk in others. As mentioned earlier, suicide is a public health crisis taking the lives of around 45,000 Americans a year and far more around the world (Centers for Disease Control \&Prevention [CDC], 2018). Furthermore, over 1 million Americans attempt suicide each year (Centers for Disease Control \&Prevention [CDC], 2018). Based on those statistics, it stands to reason that non-mental health professionals, at some point in their lives, will interact with individuals struggling with suicidal thoughts. With this information in mind, the current study aimed to examine how well non-mental health professionals can accurately recognize suicidal risk. Through research, mental health professionals have decided to focus on specific warning signs and risk factors when assessing suicidal risk.

\section{Warning Signs}

When disseminating information about suicide, mental health organizations and suicide prevention efforts utilize warning signs as a medium to educate the general public about suicide in order to increase early detection and treatment of suicidal ideation (Gould, Greenberg, Velting, \& Shaffer, 2003). Warning signs are often disseminated across the nation to those who need them most including youth, teachers, primary care providers, and mental health professionals (Nelson, 1987). Warning signs are also readily available online, but the accuracy and reliability of warning signs found online can be called into question due to the lack of 
empirical rigor required of these websites (Mandrusiak, et al., 2006). Warning signs are defined as a combination of symptoms (experiences an individual reports) and signs (observable changes in personality, sudden changes in eating habits, sudden changes in sleeping patterns, suicidal ideation, and obsession with death (Rudd et al., 2006). In 2003, The American Association of Suicidology gathered a group of suicidology experts in order to come to a consensus on suicide warning signs. After an extensive review of the literature, the panel of experts came to a consensus that the following warning signs held the most robust empirical support: "(1) Someone threatening to hurt or kill themselves; (2) Someone looking for ways to kill themselves: seeking access to pills, weapons, or other means; (3) Someone talking or writing about death, dying, or suicide; (4) Hopelessness; (5) Rage, anger, seeking revenge; (6) Acting reckless or engaging in risky activities, seemingly without thinking; (7) Feeling trapped-like there's no way out; (8) Increasing alcohol or drug use; (9) Withdrawing from friends, family, or society; (10) Anxiety, agitation, unable to sleep, or sleeping all the time; (11) Dramatic changes in mood;

(12) No reason for living; no sense of purpose in life" (Rudd et al., 2006, p. 259). Warning signs are often confused with risk factors, which while similar, represent a different set of constructs. For example, warning signs refer to the signs and symptoms of an individual, while risk factors can be found in both individuals and groups. Warning signs also refer to an immediate level of risk while risk factors only refer to an individual's likelihood of being at risk for suicide (Rudd et al., 2006).

\section{Suicide Myths}

Suicide myths are defined as misconceptions regarding suicide or suicidal individuals that have become popularized in pop culture (Domino, 1990). Common suicide myths complied from various sources include: "those who attempt suicide are mentally ill; a suicide attempt 
occurs with little warning; those who attempt suicide are less religious; those who commit suicide are depressed; a tendency to commit suicide is inherited; a person who threatens suicide will not carry out the threat; suicide attempts are histrionic gestures, looking for sympathy and/or attention; once suicidal, always suicidal; when improvement occurs, the risk is over; a person with terminal illness is unlikely to commit suicide; suicide is more frequent among specific subgroups such as the rich or the poor; if someone wants to take his own life, there is nothing that can be done to stop him" (Domino, 1990, Table 1). The majority of research conducted on suicide myths utilized an educated sample (psychologists, clinicians, nurses, social workers etc.). Research examining how less educated samples respond to suicide myths is sorely lacking.

\section{Risk Factors}

Van Orden et. al., (2010) define risk factors of suicide as characteristics that increase an individual's likelihood that they will engage in suicidal behavior. In their seminal work on the interpersonal-psychological theory of suicide, they list out risk factors in order of those with the most to least robust empirical backing. The following risk factors have more than 15 studies showing the association between them and suicidal behavior: "Mental disorder, past suicide attempts, social isolation, family conflict, unemployment, and physical illness" (Van Orden et. al., 2010). The following risk factors have 6-15 studies showing the association between them and suicidal behavior: "Family history of suicide, impulsivity, incarceration, hopelessness, seasonal variation, and serotonergic dysfunction." (Van Orden et. al., 2010, p. 47-48). The following risk factors have 5 or fewer studies showing the association between them and suicidal behavior: "Agitation or sleep dysfunction, childhood abuse, exposure to suicide, homelessness, low openness to experience, (lack of) pulling together, self-esteem, and shame." (Van Orden et. al., 2010). It is important to note that the aforementioned risk factors with seemingly little 
empirical support may in fact be significant predictors of suicide but, as of yet, they have not been studied enough to conclude that. For example, based on clinical expertise and research done on assessment tools, hopelessness is often considered a powerful risk factor of suicide even though it has not been as thoroughly researched as other risk factors (e.g. family conflict or past suicide attempts) (Van Orden et. al., 2010). The majority of studies on this topic have focused on the following risk factors: mental disorder, past suicide attempts, social isolation, family conflict, unemployment, and physical illness.

\section{Mental Disorders}

It is well established in the literature that the majority of individuals that die by suicide (90-95\%) have a diagnosed mental disorder (Cavanagh et. al, 2003; Hawton \& Van Heeringen, 2009). Furthermore, when it comes to suicidal risk, disorders are not created equal. For example, a diagnosis of schizophrenia has between a 1.8\%-5.6\% suicide rate (Palmer, Pankratz, \& Bostwick, 2005), major depressive disorder has a suicide rate between 2\%-6\% (Bostwick \& Pankratz, 2000), and borderline personality disorder has a suicide rate between 4\%-6\% (Duberstein \& Witte, 2009). When compared to the suicide rate of the general public, those diagnosed substance use disorders, conduct disorders, and bipolar disorder, are 5.7, 6, and 15 times more likely to die by suicide, respectively (Harris \& Barraclough, 1997). The aforementioned statistics illustrate how much more likely those diagnosed with these disorders are to experience suicidal ideation, but they don't indicate how much of an immediate risk each individual is at.

\section{Family Conflict}

Family conflict includes an array of familial difficulties including familial stress and domestic violence. Family conflict as a risk factor is also closely associated with Joiner's (2005), 
concept of perceived burdensomeness which argues that an individual is an increased risk of suicide if they believe themselves to be a burden on those around them, particularly in this case, their family (Van Orden et. al., 2010). Familial stress/discord is a particularly prevalent risk factor for those aged 50 years or older (Duberstein, Caine, Conner, Conwell, \& Eberly, 2004). This may be explained due to the fact elderly individuals are at higher risk of social and familial isolation (Domènech-Abella et. al., 2017).

\section{Past Suicide Attempts}

According to the large body of literature on the topic, previous suicide attempts are among the most robust predictors of suicide risk (Beautrais, 2002). As one would expect, the higher the number of past suicide attempts, the higher the risk for future attempts (Christiansen \& Jensen, 2007). According to psychological autopsy studies, one-third of those who die by suicide have at least one prior suicide attempt (Cavanagh et al., 2003) and those with a prior attempt have 40-66 times the risk for suicide than the general public (Harris \& Barraclough, 1997; Hawton, Zahl, \& Weatherall, 2003). Furthermore, 16\% of those who attempt suicide and survive will make another attempt within a year (Owens, Horrocks, \& House, 2002). When discussing suicide attempts it is important to note that there are far more suicide attempts than suicide completions. The most conservative estimates state that there are approximately 10 suicide attempts per suicide completion (Centers for Disease Control and Prevention [CDC], 2018). Women attempt suicide at a significantly higher rate than men, but this may be explained by the fact men, on average, use more lethal means than women do (Centers for Disease Control \& Prevention [CDC], 2018). In light of these statistics, it may be prudent to treat suicide attempts as seriously as suicide completions. 


\section{Social Isolation}

Social isolation includes social withdrawal, loneliness, a lack of social supports, and a sudden loss of a close relationship. As the research has repeatedly shown, social isolation is an exceedingly powerful predictor of suicidal behavior, even when various sample differences are accounted for (Joiner \& Van Orden, 2008). Similar to how family conflict is often associated with Joiner's concept of perceived burdensomeness, social isolation is closely linked to his concept of thwarted belongingness. Social isolation, particularly the facet of loneliness, have been well-studied by researchers. In fact, loneliness has been found to be even more of a risk factor of suicide for adolescents than adults (King \& Merchant, 2008).

\section{Physical Illness}

Similar to the rate discussed with suicide attempts, around one third of individuals that die by suicide were also suffering from a medical illness (Whitlock, 1986). Like with mental disorders, when it comes to suicide risk, medical illnesses are not created equal. For example, individuals with HIV/AIDS are seven times more likely to die by suicide when compared to the general population (Conwell, 1994). Brain cancer and multiple sclerosis increases an individual's suicide risk 9 and 2 times respectively (Harris \& Barraclough, 1997). Researchers believe that physical illness is more of an indirect risk factor due to the other risk factors that can influence physical illnesses. For example, an individual with a physical illness that limits mobility and independence is likely to experience social isolation as a result (Goodwin, Marusic, \& Hoven, 2003). Or an individual with a physical illness may also develop depression or another mental 
disorder due to the strain placed upon them because of their physical illness (O’Mahony, Goulet et al., 2005).

\section{Demographic Factors}

According to the most recent report by the Center for Disease Control (2018), suicide risk varies depending on certain demographic characteristics. For example, men at are a significantly higher risk for dying by suicide, while women are at a far higher rate of attempting suicide. This may be explained in part by the difference methods that men and women use to attempt suicide. Men tend to use deadlier methods such as firearms, while women use less lethal means such as poison (Centers for Disease Control \& Prevention [CDC], 2018). Suicide rates are highest among American Indians and Alaska Natives and lowest among Black people. While suicide is the $10^{\text {th }}$ leading-cause of death among Americans across all age groups, it is the $2^{\text {nd }}$ leadingcause among youth. A plethora of studies have concluded that lesbian, gay, bisexual, transgender, and queer (LGBTQ) are at a significantly higher risk for suicide than their nonLGBTQ counterparts (Grossman \& D'Augelli, 2007 \& Marshal et al., 2011). While the fact that LGBTQ youth are at increased risk for suicide has been thoroughly researched, no research has explored how well LGBTQ individuals can recognize suicide risk.

\section{Social Support}

Social support broadly defined is as "an exchange of resources between at least two individuals perceived by the provider or the recipient to be intended to enhance the well-being of the recipient" (Shumaker \& Brownell, 1984). More colloquially, social support refers to the feeling that those around you (primarily family, significant others, and friends) are there for you when you need them. More specifically, social support has been shown to be linked to lower levels of depression and other mental disorders (Spino et al., 2016). Social support has also been 
extensively studied in relation to help-seeking behaviors (Heerde \& Hemphill, 2017). Helpseeking behaviors, while varied in nature, can be defined as any behavior that assists an individual to access sources of social support, including both informal and formal sources of support (Rickwood \&Thomas, 2012). Informal supports with regards to help-seeking behaviors refers to support that is received from family, friends, and significant others, while formal support refers to support sought from professionally trained individuals like psychologist, counselors, nurses, social workers etc. (Barker, 2007). As previously stated, upwards of 50\%$70 \%$ of individuals experiencing suicidal ideation will reach out to informal supports regarding their suicidality, making their ability to accurately recognize suicidality a particular point of interest. This statistic aligns well with the importance that the IPTS places on social support and the determinate effects of thwarted belongingness (Joiner \&Van Orden, 2008).

\section{Varying Levels of Suicide Risk}

In both research and clinical settings, levels of suicide risk have been conceptualized as ranging from no risk to low risk to moderate risk to high-risk (Berman \& Silverman, 2013). While these categories may seem easily differentiated, there has been no consensus regarding a clear definition for each. There has been no research that shows the validity of each of these distinct levels but rather there exists a clinical understanding that suicide risk exists on a continuum ranging from low level to high level (Berman \& Silverman, 2013). The term "imminent risk" is often discussed with regards to policies and guidelines surrounding when a clinician should hospitalize a client/patient at risk of suicide. While states differ regarding what they consider imminent risk, they generally agree that imminent risk is comprised of an immediate risk to oneself, a likelihood of a suicide attempt soon if not stopped, an inability to care for oneself, and lastly, there needs to be concern that an attempt will occur in the near future 
(Berman, 2011). When differentiating between low risk, moderate, and high risk, clinicians examine a plethora of factors, but they often give particular attention to whether or not an individual has a plan, whether or not they have the means to carry out the attempt, and whether or not they have a history of suicide attempts. While the vary levels of suicide risk can be difficult to clearly differentiate at the lower-to-moderate levels, there seems to exist clear factors that differentiate low-to-high levels of risk (Berman \&Silverman, 2014).

\section{Mental Health Literacy}

Mental health literacy as a concept was first introduced by Australian researcher Anthony Jorm and his team of researchers in 1997 (Jorm et al., 1997). As previously mentioned, mental health literacy is defined as the knowledge and beliefs surrounding mental disorders (Jorm et al., 2006). Jorm introduced this concept to shed light on a sorely neglected area: mental health. Jorm argued that the general public lacked a basic understanding regarding mental disorders which can have significant consequences with regards to prevention, help-seeking, and treatment (Jorm et al., 2006). To illustrate this point, Jorm compared the public knowledge regarding common physical health problems like heart disease or cancer, with the public knowledge regarding mental disorders. Jorm found that the public lacked the basic knowledge about mental disorders that they seemed to possess regarding physical health problems like heart disease or cancer (Jorm, 2000). Mental health literacy is more than simply having knowledge regarding mental disorders but being able to utilize that knowledge in order to benefit the mental health of oneself or others. Mental health literacy is made up of 5 distinct components: “(a) knowledge of how to prevent mental disorders, (b) recognition of when a disorder is developing, (c) knowledge of help-seeking options and treatments available, (d) knowledge of effective self-help strategies for 
milder problems, and (e) first aid skills to support others who are developing a mental disorder or are in a mental health crisis" (Jorm, 2011, p. 231).

The research on mental health literacy has concluded several tangible consequences of the general public's relatively low level of mental health literacy including an inability to accurately recognize mental disorders, a deficient level of mental health first aid skills, and an increase in stigma regarding mental disorders (Jorm et al., 2006). Studies conducted in Australia have concluded that while mental health literacy is gradually improving, there is significant room for growth (Jorm et al., 2005). A lack of mental health literacy has also been connected with deficiencies in mental health first aid skills (Jorm et al., 2006). Mental health first aid skills are defined as skills that allow individuals (usually non-mental health professionals) to be able assist an individual dealing with a mental health concern (Kitchener \& Jorm, 2002). Research has also indicated that a lack of mental health literacy has played a factor in increasing stigma regarding mental health (Jorm et al., 2006). This relationship is particularly detrimental because stigma has been shown to be a significant barrier in help-seeking (Barney et al., 2005). Recent research has shown that, at the individual level, increasing mental health literacy has been found to bring about therapeutic effects (Christensen, Griffiths, \&Jorm, 2004; Kitchener \& Jorm, 2005). Due to the fairly recent inception of this line of research, there is not enough evidence to indicate how this would translate at the population level, but it stands to reason that whatever the outcome, improving the general public's mental health literacy will have a positive impact. Mental health literacy aims to improve the public's understanding of mental health disorders, which may improve prevention efforts, early detection, and treatment outcomes. A similar, yet more focused line of inquiry, has centered around the concept of suicide literacy. Suicide literacy is particularly 
important because a lack of suicide literacy on the part of the general public may result in suicide risk going unnoticed, which could in turn result in individuals dying in preventable suicides.

\section{Suicide Literacy}

Suicide literacy is defined as an understanding of the following facets of suicidality: Warning signs/symptoms, causes of suicidality, risk factors, and proper treatment and prevention (Batterham et al., 2013). Generally speaking, suicide literacy is mental health literacy with a specific emphasis on suicidality. Unlike mental health literacy, there has been very little research

on suicide literacy (Batterham et al., 2013). Several studies have examined specific populations and their level of suicide literacy. For example, several studies have illustrated that older individuals have a lower level of suicide literacy, even though they are more at risk for suicide than younger populations (Farrer, Leach, Griffiths, Christensen, \& Jorm, 2008; Fisher \& Goldney, 2003; Griffiths et al., 2008). This association may be explained by the fact that older populations have had less exposure to suicide than younger populations due to how suicide was more of a taboo topic in the past than it is now.

The majority of the research on suicide literacy has focused on its association with stigma regarding suicide. While it is indisputably important to research the stigmatizing beliefs/attitudes surrounding suicide because stigma can have a significant effect on help-seeking behavior (Barney et al., 2006), there exists a significant gap in the research regarding how well nonmental health professionals can apply their suicide literacy. When considering that a significant portion of those who experience suicidal ideation (50\%-70\%) (Coombs et al., 1992; Robins, Gassner, Kayes, Wilkinson, \& Murphy, 1959) reach out to family and friends (non-mental health professionals), the importance of this line of inquiry becomes apparent. The current study was particularly interested in with how well individuals of varying levels of suicide literacy could 
accurately recognize suicidal risk utilizing expertly validated vignettes. Considering the research on mental health literacy (Christensen, Griffiths, \&Jorm, 2004; Kitchener \& Jorm, 2005), it stands to reason that if an individual's suicide literacy (knowledge regarding warning signs, risk factors, myths etc.) is increased, an individual's ability to accurately recognize suicidal risk would also improve. Based on this reasoning, it was predicted that those who possess a higher level of suicide literacy will be able to more accurately recognize suicidal risk than those that possess a lower level of suicide literacy.

\section{Current Study}

As illustrated in above, there is a plethora of research on specific aspects of suicidality including warning signs, risk factors, suicide attempts, suicide myths, etc. but there is scant, if any, research on how well those in the general population can accurately recognize suicide risk. This lack of research is particularly alarming because research has shown that $50-70 \%$ of individuals contemplating suicide talk to family or friends about their suicidal thoughts (Coombs et al., 1992) making them an exceedingly important line of defense against suicide. Furthermore, a significant portion of suicide prevention programs focus on training those in the health fields to accurately assess suicide risk (Ferguson et., al 2018) with little emphasis on training the general population. The specific research questions for the current study are:

R1) Is suicide literacy associated with one's ability to accurately recognize suicide risk? H1: I hypothesized that those with lower levels of suicide literacy would be less 
effective at recognizing suicidal risk than those who with higher levels of suicide literacy.

R2) Does accuracy in assessment of suicide risk vary based on sexual orientation (e.g., lesbian, gay, bisexual, and heterosexual) or gender identity (cisgender, transgender, and nonbinary)?

H2: Due to their heightened level of suicide risk and community emphasis on suicide prevention (Grossman \& D'Augelli, 2007 and Marshal et al., 2011), I hypothesized that members of the LGBTQ community would be able to more effectively recognize suicidal risk than those that identify as non-LGBTQ. 


\section{CHAPTER III: METHOD}

\section{Participants}

At the conclusion of the study, 289 participants completed the survey in its entirety. Of the 289 participants, the vast majority (91\%) were between the ages of 18-22. Of those who completed the study, 39\% of the participants were first-year students, $23 \%$ were second-year students, $24 \%$ were third-year students, $9 \%$ were fourth-year students, and 3\% were fifth-year students or above. With regards to gender, $74 \%$ of participants identified as Cisgender women, $18 \%$ identified as Cisgender men, $4 \%$ identified as Non-Binary, $1 \%$ identified as Transgender men, and $2 \%$ of participants identities did not fit the aforementioned gender identities. With regards to sexual orientation, 79\% identified as Straight, 10\% identified as Bisexual, 4\% identified as Lesbian, $2 \%$ identified as Gay, and 3\% of the participants identities did not fit the aforementioned sexual orientations. With regards to ethnicity, $73 \%$ of the participants identified as Caucasian, 8\% identified as African-American/Black, 8\% identified as Hispanic, 6\% identified as Latino, 0.88\% identified as East Asian, 0.59\% identified as South Asian, 0.29\% identified as Middle Eastern, 0.29\% identified as Native American, 0.29\% identified as Hawaiian/Pacific Islander, and 1\% of participants ethnicities did not fit the aforementioned ethnic groups.

While not part of the primary research questions, we were also interested in examining whether individual's exposure to suicide had any influence on their ability to accurately recognize suicide risk. To examine this, we asked the following questions: "How often do family and friends talk to you about suicide?", "How often do family and friends talk to you about experiencing suicidal thoughts?", and "How often have your family and friends talked to you about attempting suicide?". A breakdown of participants answers to these questions is presented 
in Table 1. The majority of the participants were recruited through the Illinois State University Psychology (ISU) Online Participant System (SONA). The remainder of the participants were recruited through an email sent out the ISU Pride group, which is a group primarily made up of LGBTQ students at ISU.

\section{Instruments}

\section{Demographic Survey}

Participants completed a 9-item demographic survey asking them question about their age, year in school, gender, sexual orientation, ethnicity, whether or not they have received training on suicide prevention in the past, and general exposure to suicide. Demographic information was be gathered in order to ascertain whether individuals with differing backgrounds perform differently when assessing suicidal risk. For example, LGBTQ individuals are at significantly increased risk of suicide (Haas \& Lane, 2015) but does that mean that individuals who are a part of the LGBTQ community are more or less accurate at assessing suicidal risk than heterosexual individuals?

\section{Suicide Risk Vignettes}

Each participant read through four expertly validated vignettes that detailed varying levels of suicide risk. Three experts in crisis and suicide assessment from the field of school psychology utilized the suicide matrix found in Figure 1 in order to validate these vignettes. In addition to scoring these vignettes, the experts discussed them and provided the author feedback as to increase their validity. There was $100 \%$ agreement among the raters regarding which vignette represented no, low, medium, and high risk. The first is the control vignette which details an individual at no risk of suicide. The second vignette is a case containing minimal suicide risk, the third details a case with moderate suicide risk, and the fourth details a case of 
high suicide risk. These vignettes contain well-researched and robust warning signs and risk factors of suicide like changes in personality, suicidal ideation, social isolation, and interpersonal conflict (Rudd et al., 2006; Van Orden et. al., 2010). These vignettes were counterbalanced in order to control for order effects. Participants were asked to respond to each vignette according to what they believed the suicide risk was for each scenario. Each vignette had one accurate level of suicide risk (i.e. one correct answer). Incorrect answers on the vignettes were scored as " 0 " and each correct answer was scored as "1". Participants received an assessment accuracy score of 0-4 to denote their ability to accurately recognize suicide risk in others. These vignettes can be found in Appendix B.

Figure 1. Suicide risk matrix ranging from low risk, medium risk, and higher risk.

\begin{tabular}{|c|c|c|c|}
\hline & Low Risk & Medium Risk & High Risk \\
\hline $\begin{array}{ll}\text { 1. } & \text { Current Suicide Plan } \\
\text { A. Details? } \\
\text { B. How Prepared? } \\
\text { C. How Soon? } \\
\text { D. Method? } \\
\text { E. Chance of } \\
& \text { Intervention? }\end{array}$ & $\begin{array}{l}\text { A. Vague } \\
\text { B. Means not available } \\
\text { C. No specific time } \\
\text { D. Pills, slash wrists } \\
\text { E. Others present most of } \\
\text { time }\end{array}$ & $\begin{array}{ll}\text { A. Some specifics } \\
\text { B. Has means close by } \\
\text { C. Within a few } \\
\text { days/hours } \\
\text { D. Drugs/alcohol, car } \\
\text { wreck } \\
\text { E. Others available if } \\
\text { called upon } \\
\end{array}$ & $\begin{array}{l}\text { A. Well thought out } \\
\text { B. Has means in hand } \\
\text { C. Immediately } \\
\text { D. Gun, hanging, jumping } \\
\text { E. Isolated }\end{array}$ \\
\hline $\begin{array}{ll}\text { 2. Pain } \\
\text { A. Bearable? } \\
\text { B. Desperation? } \\
\text { C. Coping skills? }\end{array}$ & $\begin{array}{l}\text { A. Pain is bearable } \\
\text { B. Wants pain to stop, } \\
\text { but not desperate } \\
\text { C. Identifies ways to stop } \\
\text { the pain }\end{array}$ & $\begin{array}{l}\text { A. Pain is almost } \\
\text { unbearable } \\
\text { B. Becoming desperate } \\
\text { for relief } \\
\text { C. Limited ways to cope } \\
\text { with pain }\end{array}$ & $\begin{array}{l}\text { A. Pain is unbearable } \\
\text { B. Desperate for relief } \\
\text { from pain } \\
\text { C. Will do anything for } \\
\text { stop the pain }\end{array}$ \\
\hline $\begin{array}{ll}\text { 3. } & \text { Resources } \\
\text { A. Availability of } \\
\text { resources? }\end{array}$ & $\begin{array}{l}\text { A. Help available; } \\
\text { acknowledges that } \\
\text { significant others are } \\
\text { concerned and } \\
\text { available to help }\end{array}$ & $\begin{array}{l}\text { A. Family and friends } \\
\text { available, but are not } \\
\text { perceived by the } \\
\text { student to be willing to } \\
\text { help }\end{array}$ & $\begin{array}{l}\text { A. Family and friends are } \\
\text { not available and/or are } \\
\text { hostile, injurious, } \\
\text { exhausted }\end{array}$ \\
\hline $\begin{array}{l}\text { 4. Prior Suicidal } \\
\text { Behavior of.... } \\
\text { A. Self } \\
\text { B. Significant other }\end{array}$ & $\begin{array}{l}\text { A. No prior suicidal } \\
\text { behavior } \\
\text { B. No significant others } \\
\text { have engaged in } \\
\text { suicidal behavior }\end{array}$ & $\begin{array}{l}\text { A. One previous low- } \\
\text { lethality attempt; } \\
\text { history of threats } \\
\text { B. Significant others have } \\
\text { recently attempted } \\
\text { suicidal behavior }\end{array}$ & $\begin{array}{l}\text { A. One attempt of high } \\
\text { lethality, or multiple } \\
\text { attempts of moderate } \\
\text { lethality } \\
\text { B. Significant others have } \\
\text { recently committed } \\
\text { suicide }\end{array}$ \\
\hline
\end{tabular}




\begin{tabular}{|c|c|c|c|}
\hline $\begin{array}{ll}\text { 5. } & \text { Mental health } \\
\text { A. Mental illness } \\
\text { B. Coping behavior } \\
\text { C. Depression } \\
\text { D. Medical Status } \\
\text { E. Other } \\
\\
\text { Psychopathology }\end{array}$ & 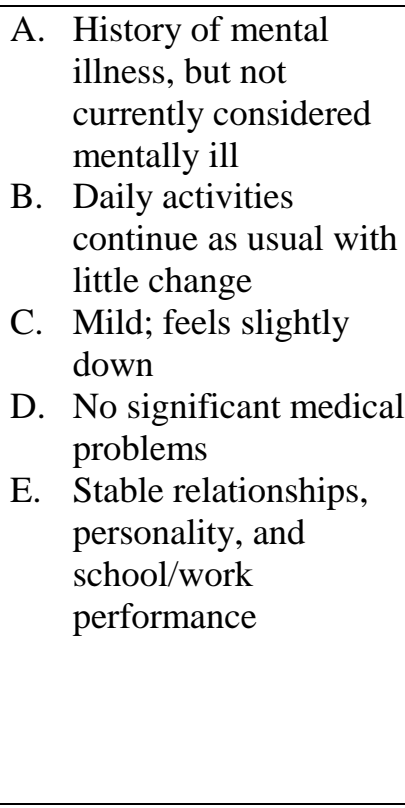 & 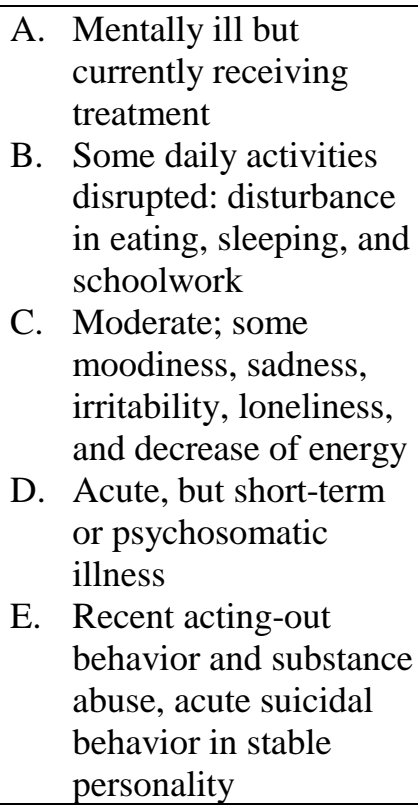 & 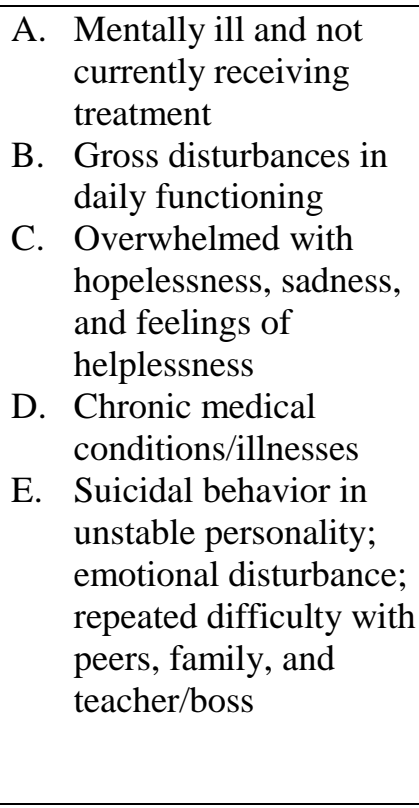 \\
\hline $\begin{array}{l}\text { 6. Stress } \\
\text { A. Level of stress }\end{array}$ & B. No significant stress & $\begin{array}{l}\text { A. Moderate reaction to } \\
\text { loss and environmental } \\
\text { changes }\end{array}$ & $\begin{array}{l}\text { A. Severe reaction to loss } \\
\text { or environmental } \\
\text { changes }\end{array}$ \\
\hline Total Checks & & & \\
\hline
\end{tabular}

Note. Adapted from "Suicide Risk Assessment Summary Sheet," by D. N, Miller \& S. E. Brock, 2010, Identifying, Assessing, and Treating Self-Injury at School, p. 45. Copyright 2010 by Springer.

Originally based on a checklist developed by Ryan-Arredondo et al. (2001)

Table 1.

Exposure to Suicide

\begin{tabular}{llll}
\hline & $\mathrm{N}$ & Mean & SD \\
\hline $\begin{array}{l}\text { How often do family } \\
\text { and friends talk to } \\
\text { you about suicide? }\end{array}$ & 289 & 2.13 & .870 \\
$\begin{array}{l}\text { How often do family } \\
\text { and friends talk to }\end{array}$ & 289 & 1.79 & .838 \\
$\begin{array}{l}\text { you about } \\
\text { experiencing suicidal } \\
\text { thoughts? }\end{array}$ & & \\
$\begin{array}{l}\text { How often have your } \\
\text { family and friends } \\
\text { talked to you about } \\
\text { attempting suicide? }\end{array}$ & 289 & 1.58 & \\
\end{tabular}

Note: $1=$ Never, $2=$ Rarely, $3=$ Sometimes, $4=$ Often, and $5=$ Almost Always. 


\section{Literacy of Suicide Scale}

Participants were asked to complete a validated 26-item Literacy of Suicide Scale. This scale focuses on the four domains of suicide literacy as defined by (Jorm, 2000): “(a) signs and symptoms, (b) causes of the nature of suicidality, (c) risk factors, and (d) treatment and prevention." (Batterham et al., 2013). Each of the items are answered as "True", "False", or "I don't know”. Incorrect or "I don’t know" answers are scored as “ 0 ”, while correct answers are scored as "1". Suicide literacy scores are the sum of all the correct answers, meaning higher scores indicate a higher level of suicide literacy. This scale also included an attention check in order to filter-out participants who were carelessly responding to the items. The Literacy of Suicide Scale was validated in a previous study using item-response theory approach since each item has a correct response (Batterham et al., 2013). Further information regarding the validity of this scale is not accessible at this time. The Cronbach's alpha coefficient for the current sample = .72.

\section{Procedure}

Participants were recruited through the Illinois State University Psychology Online Participant System (SONA) and through an email sent out to the ISU Pride group, which is a group primarily made up of LGBTQ students at ISU. This study was conducted solely online. The participants began the study by reading and agreeing to the informed consent form. After they agreed to the informed consent, participants were redirected to a Qualtrics survey that included the demographic survey, the suicide risk vignettes, and the Literacy of Suicide Scale. The suicide risk vignettes were presented in randomized order using the Qualtrics randomizer setting. The Literacy of Suicide Scale and the suicide risk vignettes were also randomly counterbalanced to control for order effects. Lastly, participants were also provided contact 
information for both the Student Counseling Services at Illinois State University and the National Suicide Prevention Lifeline, which would allow participants to access crisis services if required. According to the Qualtrics, which tracked how long it took each participant to complete the survey, this study took roughly 15 minutes for most participants to complete. These procedures were approved by the Illinois State University Institutional Review Board (IRB). For their participation in this research study, participants received a half-credit towards one of their psychology courses.

\section{Data Analysis}

Correlational analyses were conducted as a preliminary step to examining the data. To examine research question one, I utilized regression to analyze the association between accuracy on the suicide risk vignettes and suicide literacy with suicide literacy as the independent variable and accuracy on the suicide risk vignettes as the dependent variable. To examine research question two, I utilized one-way analyses of variance (ANOVA) to compare the differences in accuracy on the suicide risk vignettes LGBTQ individuals and non-LGBTQ individuals. 


\section{CHAPTER IV: RESULTS}

\section{Correlations}

Age, sexual orientation, and accuracy on the high-risk vignette were all found to be positively correlated with suicide literacy. Accuracy on the high-risk vignette was found to positively correlated with accuracy on the moderate-risk, low-risk, and no-risk vignettes. Accuracy on the moderate-risk vignette was also correlated with accuracy on the low-risk vignette but was not correlated with accuracy on the no-risk vignette. Lastly, accuracy on the norisk vignette was positively correlated with accuracy on the low-risk vignette. The results for all of the correlations that were examined for this study can be found in Table 2 .

\section{Research Question 1}

Research question 1 examines whether suicide literacy associated with one's ability to accurately recognize suicide risk? Suicide literacy was assessed using the suicide literacy score (0-26) participants received after completing the LOSS. Recognition of suicide risk in others was assessed using the assessment accuracy score (0-4) that participants received after completing the suicide risk vignettes. Each of these vignettes contain well-established suicide risk factors and warning signs (Rudd et al., 2006; Van Orden et. al., 2010). Regression was used to analyze whether suicide literacy is associated with ability to accurately recognize suicide risk in others. It was hypothesized that those with lower levels of suicide literacy would be less effective at recognizing suicidal risk than those who with higher levels of suicide literacy. The association between suicide literacy and total suicide risk accuracy (i.e., how accurate they were across all four scenarios) was not significant, $\mathrm{F}(1,288)=1.16, p=.282$. While the association across all four vignettes was not significant, while examining each vignette in isolation, it was discovered that the association between suicide literacy and recognition of suicide risk was significant for 
the high-risk vignette, $\mathrm{F}(1,288)=9.91, p=.002$. The association for the moderate-risk, low-risk, and no-risk vigneRQttes were all non-significant $(\mathrm{F}(1,288)=0.41, p=.521, \mathrm{~F}(1,288)=0.58, p$ $=.446, \mathrm{~F}(1,288)=0.20, p=.658$, respectively). This indicates that those with higher suicide literacy scores were more accurate at identifying high-risk suicide situations when compared to participants with lower suicide literacy. However, suicide literacy was not associated with accuracy for other risk categories.

\section{Research Question 2}

Research question 2 examines whether LGBTQ individuals are more or less accurate in their assessment of suicide risk than non-LGBTQ individuals. A series of ANOVAs were utilized to examine the difference between LGBTQ participants and non-LGBTQ participants with regards to their ability to accurately recognize suicide risk in others. Due to their heightened level of suicide risk and community emphasis on suicide prevention (Grossman \& D’Augelli, 2007 and Marshal et al., 2011), it was hypothesized that members of the LGBTQ community would be able to more effectively recognize suicidal risk than those that identify as non-LGBTQ. Due to the way the sample was setup, sexual orientation and gender identity were examined separately. There was no significant difference between LGBTQ (sexual orientation) individuals and non-LGBTQ individual's ability to accurately recognize suicide risk, $\mathrm{F}(4,288)=0.55, p=$ .692. Table 3 details the breakdown of the differences based on each sexual orientation identity group (Gay, Bisexual, Lesbian, etc.). There was also no significant difference between LGBTQ (gender identity) individuals and non-LGBTQ individual's ability to accurately recognize suicide risk. Table 4 details the breakdown of the differences based on each gender identity group (Transgender men, Transgender women, Non-Binary etc.). 


\section{Exploratory Analyses: Suicide Literacy}

In addition to the main research question, some analyses were conducted to explore the data. Of particular interest was the association between suicide literacy and other study variables. Table 5 lists each item of the LOSS with their corresponding correct answer and the percentage of the sample that responded correctly. The mean score on the LOSS across the whole sample was $16.3(\mathrm{SD}=3.4)$. Participants in this sample demonstrated a lower level of suicide literacy when compared with a recent study conducted in Australia by the creator of the LOSS (Batterham et al., 2013). This difference in suicide literacy is particularly evident when certain items are compared. For example, with regards to the following item: "Men are more likely to suicide than women (True)" only $38 \%$ of this study's sample was able to accurately respond, compared to $62 \%$ in the aforementioned sample. While there was no significant difference between LGBTQ individuals and non-LGBTQ individuals with regards to their ability to accurately recognize suicide risk, LGBTQ (with regards to their sexual orientation) individuals had significantly higher suicide literacy scores than their non-LGBTQ counterparts, F $(4,288)=$ $3.48, \mathrm{p}<.01$. Post doc analyses indicated that differences were significant between heterosexual participants and lesbian $(\mathrm{p}<.05)$ as well as bisexual $(\mathrm{p}<.01)$ participants (see Table 6$)$. That is, participants identifying as lesbian or bisexual scored significantly higher on the test of suicide literacy when compared to heterosexual participants. On the other hand, those there was no significant difference between those that identified as LGBTQ with regards to their gender identity and their non-LGBTQ counterparts, $\mathrm{F}(4,288)=7.33, \mathrm{p}=.646$ (see Table 7)

\section{General Findings: Accurate Recognition of Suicide Risk}

Accurate recognition of suicide risk was examined using four expertly validated vignettes that ranged from no risk to high suicide risk. Incorrect answers on the vignettes were scored as 
"0" and each correct answer was scored as "1". After completing all four vignettes, participants received an assessment accuracy score of 0-4 to denote their ability to accurately recognize suicide risk in others. Table 8 lists each vignette with their corresponding correct answer and the percentage of the sample that responded correctly. The mean score for the vignettes across the whole sample was $2.6(\mathrm{SD}=1.1)$. The mean score for the high-risk vignette was $.73(\mathrm{SD}=.44)$, the mean score for the moderate risk vignette was $.57(\mathrm{SD}=.49$ ), the mean score for the low risk vignette $.63(\mathrm{SD}=.48)$, and the mean score for the no risk vignette $.46(\mathrm{SD}=.46)$. 
Table 2 .

Correlations

\begin{tabular}{|c|c|c|c|c|c|c|c|c|c|}
\hline Variable & 1 & 2 & 3 & 4 & 5 & 6 & 7 & 8 & 9 \\
\hline 1. Gender & 1.0 & & & & & & & & \\
\hline 2. Age & .05 & 1.0 & & & & & & & \\
\hline 3. Ethnicity & -.06 & -.07 & 1.0 & & & & & & \\
\hline $\begin{array}{ll}\text { 4. } & \text { Sexual } \\
\text { Orientation }\end{array}$ & .11 & .10 & .05 & 1.0 & & & & & \\
\hline $\begin{array}{l}\text { 5. Suicide } \\
\text { Literacy }\end{array}$ & -.02 & $.16^{* *}$ & .07 & $.17 * *$ & 1.0 & & & & \\
\hline 6. High-Risk & -.06 & -.00 & .05 & .10 & $.18 * *$ & 1.0 & & & \\
\hline $\begin{array}{l}\text { 7. Moderate- } \\
\text { Risk }\end{array}$ & .05 & -.00 & .05 & -.02 & -.04 & $.16^{* *}$ & 1.0 & & \\
\hline 8. Low-Risk & -.11 & -.05 & -.09 & -.04 & .04 & $.21 * *$ & $.13^{* *}$ & 1.0 & \\
\hline 9. No-Risk & .00 & -.02 & .07 & -.07 & -.03 & $.14 * *$ & .09 & $.14 * *$ & 1.0 \\
\hline
\end{tabular}

Table 3.

Suicide Risk Assessment Accuracy Comparison Across Sexual Orientations

\begin{tabular}{lllll}
\hline Sexual Orientation & Sexual & Mean Difference & SD & $p$ \\
& Orientation & & \\
\hline Heterosexual & Gay & -.544 & .469 & .25 \\
& Lesbian & .039 & .335 & .91 \\
& Bisexual & .159 & .227 & .48 \\
& Other & -.234 & .435 & .59
\end{tabular}

(Table Continues) 
Table 3. Continued

\begin{tabular}{|c|c|c|c|c|}
\hline \multirow[t]{2}{*}{ Sexual Orientation } & Sexual & Mean Difference & $\mathrm{SD}$ & $p$ \\
\hline & \multicolumn{4}{|l|}{ Orientation } \\
\hline \multirow[t]{4}{*}{ Gay } & Heterosexual & .544 & .469 & .25 \\
\hline & Lesbian & .583 & .567 & .30 \\
\hline & Bisexual & .702 & .510 & .17 \\
\hline & Other & .309 & .631 & .62 \\
\hline \multirow[t]{4}{*}{ Lesbian } & Heterosexual & -.039 & .335 & .91 \\
\hline & Gay & -.583 & .567 & .30 \\
\hline & Bisexual & .119 & .391 & .76 \\
\hline & Other & -.274 & .539 & .61 \\
\hline \multirow[t]{4}{*}{ Bisexual } & Heterosexual & -.159 & .227 & .48 \\
\hline & Gay & -.702 & .510 & .17 \\
\hline & Lesbian & -.119 & .391 & .76 \\
\hline & Other & -.393 & .479 & .41 \\
\hline \multirow[t]{4}{*}{ Other } & Heterosexual & .234 & .435 & .59 \\
\hline & Gay & -.309 & .631 & .62 \\
\hline & Lesbian & .274 & .539 & .61 \\
\hline & Bisexual & .393 & .479 & .41 \\
\hline
\end{tabular}


Table 4.

Suicide Risk Assessment Accuracy Comparison Across Gender Identities

\begin{tabular}{|c|c|c|c|c|}
\hline Gender Identity & Gender & Mean Difference & SD & $\bar{p}$ \\
\hline & Identity & & & \\
\hline \multirow[t]{4}{*}{ Cis Man } & Cis Woman & .237 & .174 & .89 \\
\hline & Trans Man & .654 & .814 & .42 \\
\hline & Non-Binary & -.246 & .390 & .53 \\
\hline & Other & .820 & .487 & .09 \\
\hline \multirow[t]{4}{*}{ Cis Woman } & Cis Man & -.024 & .174 & .89 \\
\hline & Trans Man & .630 & .802 & .43 \\
\hline & Non-Binary & -.270 & .365 & .46 \\
\hline & Other & .797 & .467 & .09 \\
\hline \multirow[t]{4}{*}{ Trans Man } & Cis Man & -.654 & .814 & .42 \\
\hline & Cis Woman & -.630 & .802 & .43 \\
\hline & Non-Binary & -.900 & .875 & .30 \\
\hline & Other & .167 & .922 & .86 \\
\hline \multirow[t]{4}{*}{ Non-Binary } & Cis Man & .246 & .390 & .53 \\
\hline & Cis Woman & .270 & .365 & .46 \\
\hline & Trans Man & .900 & .875 & .30 \\
\hline & Other & 1.07 & .583 & .070 \\
\hline Other & Cis Man & -.820 & .487 & .09 \\
\hline
\end{tabular}

(Table Continues) 
Table 4. Continued

\begin{tabular}{lllll}
\hline Gender Identity & Gender & Mean Difference & SD & $p$ \\
& Identity & & & \\
\hline Cis Woman & -.797 & .467 & .09 \\
Trans Man & -.167 & .922 & .86 \\
Non-Binary & -1.07 & .583 & .07
\end{tabular}

Note: Trans Women are excluded from this table due to the fact that none of the participants identified as Trans Women.

Table 5.

Literacy of Suicide Scale (LOSS) Correct Responses

\begin{tabular}{llc}
\hline Item & N Correct & $\%$ Correct \\
\hline $\begin{array}{l}\text { Nothing can be done to stop } \\
\text { people from making the attempt } \\
\text { once they have made up their } \\
\text { minds to kill themselves (F) }\end{array}$ & $94 \%$ & \\
$\begin{array}{l}\text { If assessed by a psychiatrist, } \\
\text { everyone who suicides would } \\
\text { be diagnosed as depressed (F) }\end{array}$ & 198 & $68 \%$ \\
$\begin{array}{l}\text { Seeing a psychiatrist or } \\
\text { psychologist can help prevent } \\
\text { someone from suicide (T) }\end{array}$ & 256 & $88 \%$ \\
$\begin{array}{l}\text { Most people who suicide are } \\
\text { psychotic (F) }\end{array}$ & 271 & $93 \%$ \\
$\begin{array}{l}\text { Only experts can help people } \\
\text { who want to suicide (F) }\end{array}$ & 279 & $96 \%$ \\
$\begin{array}{l}\text { There is a strong relationship } \\
\text { between alcoholism and suicide } \\
\text { (T) }\end{array}$ & 114 & $39 \%$ \\
$\begin{array}{l}\text { People who talk about suicide } \\
\text { rarely kill themselves (F) }\end{array}$ & 154 & \\
\hline
\end{tabular}

(Table Continues) 
Table 5. Continued

\begin{tabular}{|c|c|c|}
\hline Item & N Correct & $\%$ Correct \\
\hline $\begin{array}{l}\text { People who want to attempt } \\
\text { suicide can change their mind } \\
\text { quickly }(\mathrm{T})\end{array}$ & 108 & $37 \%$ \\
\hline $\begin{array}{l}\text { People who want to attempt } \\
\text { suicide can change their mind } \\
\text { quickly }(\mathrm{T})\end{array}$ & 108 & $37 \%$ \\
\hline $\begin{array}{l}\text { Talking about suicide always } \\
\text { increases the risk of suicide }(F)\end{array}$ & 203 & $70 \%$ \\
\hline $\begin{array}{l}\text { A person who has made a past } \\
\text { suicide attempt is more likely to } \\
\text { attempt suicide again than } \\
\text { someone who has never } \\
\text { attempted (T) }\end{array}$ & 177 & $61 \%$ \\
\hline $\begin{array}{l}\text { Media coverage of suicide will } \\
\text { inevitably encourage other } \\
\text { people to attempt suicide }(F)\end{array}$ & 130 & $44 \%$ \\
\hline $\begin{array}{l}\text { Not all people who attempt } \\
\text { suicide plan their attempt in } \\
\text { advance }(T)\end{array}$ & 219 & $75 \%$ \\
\hline $\begin{array}{l}\text { People who have thoughts } \\
\text { about suicide should not tell } \\
\text { others about it }(\mathrm{F})\end{array}$ & 274 & $94 \%$ \\
\hline $\begin{array}{l}\text { Very few people have thoughts } \\
\text { about suicide }(F)\end{array}$ & 259 & $89 \%$ \\
\hline $\begin{array}{l}\text { People who are anxious or } \\
\text { agitated have a higher risk of } \\
\text { suicide }(\mathrm{T})\end{array}$ & 164 & $56 \%$ \\
\hline $\begin{array}{l}\text { Most people who suicide are } \\
\text { younger than } 30(\mathrm{~F})\end{array}$ & 61 & $21 \%$ \\
\hline $\begin{array}{l}\text { Men are more likely to suicide } \\
\text { than women }(\mathrm{T})\end{array}$ & 112 & $38 \%$ \\
\hline $\begin{array}{l}\text { People with relationship } \\
\text { problems or financial problems } \\
\text { have a higher risk of suicide }(\mathrm{T})\end{array}$ & 220 & $76 \%$ \\
\hline
\end{tabular}


Table 5. Continued

\begin{tabular}{|c|c|c|}
\hline Item & N Correct & $\%$ Correct \\
\hline $\begin{array}{l}\text { Most people who suicide don't } \\
\text { make future plans }(\mathrm{F})\end{array}$ & 127 & $43 \%$ \\
\hline $\begin{array}{l}\text { If you asked someone directly } \\
\text { "'Do you feel like killing } \\
\text { yourself?', it will likely lead } \\
\text { that person to make a suicide } \\
\text { attempt (F) }\end{array}$ & 204 & $70 \%$ \\
\hline $\begin{array}{l}\text { A suicidal person will always } \\
\text { be suicidal and entertain } \\
\text { thoughts of suicide }(\mathrm{F})\end{array}$ & 219 & $75 \%$ \\
\hline $\begin{array}{l}\text { A person who suicides is } \\
\text { mentally ill }(\mathrm{F})\end{array}$ & 133 & $46 \%$ \\
\hline $\begin{array}{l}\text { A time of high suicide risk in } \\
\text { depression is at the time when } \\
\text { the person begins to improve } \\
\text { (T) }\end{array}$ & 55 & $19 \%$ \\
\hline $\begin{array}{l}\text { Motives and causes of suicide } \\
\text { are readily established }(\mathrm{F})\end{array}$ & 167 & $57 \%$ \\
\hline $\begin{array}{l}\text { Most people who attempt } \\
\text { suicide fail to kill themselves } \\
\text { (T) }\end{array}$ & 100 & $34 \%$ \\
\hline $\begin{array}{l}\text { Those who attempt suicide do } \\
\text { so only to manipulate others } \\
\text { and attract attention to } \\
\text { themselves }(\mathrm{F})\end{array}$ & 258 & $89 \%$ \\
\hline
\end{tabular}

Note: $\mathrm{T}$ and $\mathrm{F}$ denote the correct response to each item. 
Table 6.

Suicide Literacy Comparison Across Sexual Orientations

\begin{tabular}{|c|c|c|c|c|}
\hline \multirow[t]{2}{*}{ Sexual Orientation } & Sexual & Mean Difference & $\overline{S D}$ & $\bar{p}$ \\
\hline & \multicolumn{4}{|l|}{ Orientation } \\
\hline \multirow[t]{4}{*}{ Heterosexual } & Gay & 1.28 & 1.36 & .35 \\
\hline & Lesbian & -2.38 & .978 & .01 \\
\hline & Bisexual & -1.78 & .660 & .01 \\
\hline & Other & -.885 & 1.27 & .48 \\
\hline \multirow[t]{4}{*}{ Gay } & Heterosexual & -1.28 & 1.36 & .35 \\
\hline & Lesbian & -3.67 & 1.65 & .03 \\
\hline & Bisexual & -3.06 & 1.49 & .04 \\
\hline & Other & -2.17 & 1.84 & .24 \\
\hline \multirow[t]{4}{*}{ Lesbian } & Heterosexual & 2.39 & .978 & .01 \\
\hline & Gay & 3.67 & 1.65 & .03 \\
\hline & Bisexual & .607 & 1.14 & .59 \\
\hline & Other & 1.50 & 1.57 & .34 \\
\hline \multirow[t]{4}{*}{ Bisexual } & Heterosexual & 1.78 & .660 & .01 \\
\hline & Gay & 3.06 & 1.49 & .04 \\
\hline & Lesbian & -.607 & 1.14 & .59 \\
\hline & Other & .893 & 1.40 & .52 \\
\hline
\end{tabular}

(Table Continues) 
Table 6. Continued

\begin{tabular}{lllll}
\hline Sexual Orientation & Sexual & Mean Difference & SD & \\
& Orientation & & & \\
\hline Other & Heterosexual & & 1.27 & .48 \\
& Gay & 2.17 & 1.84 & .24 \\
& Lesbian & -1.50 & 1.57 & .34 \\
& Bisexual & -.893 & 1.40 & .52 \\
\hline
\end{tabular}

Table 7.

Suicide Literacy Comparison Across Gender Identities

\begin{tabular}{|c|c|c|c|c|}
\hline Gender Identity & Gender Identity & Mean Difference & $\mathrm{SD}$ & $P$ \\
\hline \multirow[t]{4}{*}{ Cis Man } & Cis Woman & -.374 & .520 & .47 \\
\hline & Trans Man & -2.40 & 2.43 & .32 \\
\hline & Non-Binary & -.304 & 1.16 & .79 \\
\hline & Other & 1.26 & 1.45 & .38 \\
\hline \multirow[t]{4}{*}{ Cis Woman } & Cis Man & .374 & .520 & .47 \\
\hline & Trans Man & -2.03 & 2.39 & .40 \\
\hline & Non-Binary & .070 & 1.09 & .95 \\
\hline & Other & 1.64 & 1.39 & .24 \\
\hline \multirow[t]{4}{*}{ Trans Man } & Cis Man & 2.40 & 2.43 & .32 \\
\hline & Cis Woman & 2.03 & 2.39 & .40 \\
\hline & Non-Binary & 2.10 & 2.61 & .42 \\
\hline & Other & 3.67 & 2.75 & .18 \\
\hline
\end{tabular}


Table 7. Continued

\begin{tabular}{lllll}
\hline Gender Identity & Gender Identity & Mean Difference & SD & $P$ \\
\hline Non-Binary & Cis Man & .304 & 1.16 & .79 \\
& Cis Woman & -.070 & 1.09 & .95 \\
& Trans Man & -2.10 & 2.61 & .42 \\
& Other & 1.57 & 1.74 & .37 \\
Cther & Cis Man & -1.26 & 1.45 & .38 \\
& Cis Woman & -1.64 & 1.39 & .24 \\
& Trans Man & -3.67 & 2.75 & .37 \\
& Non-Binary & -1.57 & 1.74 & .37 \\
\hline
\end{tabular}

Note: Trans Women are excluded from this table due to the fact that none of the participants identified as Trans Women.

Table 8.

Suicide Risk Vignettes Correct Responses

\begin{tabular}{lcc}
\hline Item & N Correct & \% Correct \\
\hline High Risk Vignette & 212 & $73 \%$ \\
Moderate Risk Vignette & 166 & $57 \%$ \\
Low Risk Vignette & 181 & $62 \%$ \\
No Risk Vignette & 199 & $68 \%$ \\
& & \\
\hline
\end{tabular}




\section{Additional Findings}

With regards to the suicide risk vignettes, participants' proximity to the correct response was also examined, meaning that some responses were more accurate than others. For example, if the participant rated a scenario as moderate risk when the correct answer was high risk, this was coded as 1 to indicate that were off by 1 point. If the correct answer was high risk and they indicated no risk, this was coded as 3 as they were 3 points away from the correct answer. Thus, the higher the proximity the score, the less accurate they were in assessing suicide risk.

Proximity to accuracy was significant for the high-risk vignette for suicide literacy $(\beta=-.21, p<$ $.01 ; \mathrm{F}(1,288)=13.48, p<.01)$. Meaning that those with higher levels of suicide literacy were closer to being accurate than those with lower levels of suicide literacy. For example, those with higher literacy, even when responding incorrectly to the high-risk vignette, were able to recognize that the vignette contained moderate-low risk. The mean score for proximity to accuracy for the high-risk, moderate-risk, low-risk, and no- risk vignettes were $.34(\mathrm{SD}=.62)$, $.44(\mathrm{SD}=.52), .40(\mathrm{SD}=.54)$, and $.37(\mathrm{SD}=.61)$, respectively.

Each participants exposure to suicide was also gathered and was examined through the use of three items in the demographic survey. The items were as follows: "How often do family and friends talk to you about suicide?", "How often do family and friends talk to you about experiencing suicidal thoughts?", and "How often have your family and friends talked to you about attempting suicide?'. Participants responded to these items on a 5-point Likert scale $(1=$ Never, $2=$ Rarely, $3=$ Sometimes, $4=$ Often, and $5=$ Almost Always). The mean scores for the first, second, and third exposure items were $2.13(\mathrm{SD}=.87), 1.79(\mathrm{SD}=.84)$, and $1.58(\mathrm{SD}=$ .72) respectively. While communication regarding suicide was associated with increased literacy $(\beta=.17, p<.01, \beta=.18, p<.01, \beta=.25, p<.01$, respectively $)$, these variables were not 
associated with accuracy $(\beta=.09, p=.11, \beta=-.04, p=.46, \beta=.03, p=.62$, respectively). Interestingly, there were differences among participants regarding how often they discussed suicide with friends and family $(\mathrm{F}(4,288)=6.13, p<.01)$. Participants identifying as bisexual reported discussing suicide more often with friends and family when compared to participants who identified as heterosexual $\left(\mathrm{M}_{\mathrm{diff}}=.72, p<.01\right)$. The same was found for discussions around suicidal thoughts $(\mathrm{F}(4,288)=11.06, p<.01)$, with bisexual individuals indicating this occurred more for them when compared to frequency reports of heterosexual participants $\left(\mathrm{M}_{\mathrm{diff}}=.95, p<\right.$ $.01)$.. This was also true for discussions regarding suicidal attempts $(\mathrm{F}(4,288)=6.03, p<.01$; $\left.\mathrm{M}_{\mathrm{diff}}=.62, p<.01\right)$. Gender identity was not associated with differences in how often participants discussed suicide with friends and family $(\mathrm{F}(4,288)=1.53, p=.19)$, discussed suicidal thoughts $(\mathrm{F}(4,288)=1.57, p=.18)$, or discussed suicide attempts $(\mathrm{F}(4,288)=1.09, p=$ $.36)$. 


\section{CHAPTER V: DISCUSSION}

Suicide is a national public health crisis that has recently surpassed homicide as the $2^{\text {nd }}$ leading-cause of death among youth in the United States (Centers for Disease Control \& Prevention [CDC], 2018). Research has demonstrated that upwards of 50\%-70\% of those struggling with suicidal thoughts discuss their thoughts with family or friends (Coombs et al., 1992). It is highly unlikely that these family members and friends are mental health professionals, meaning that they may struggle to accurately recognize suicide risk. Mental health professionals are trained to recognize suicide risk, but non-mental health professionals are rarely trained on this subject, even though those at risk may reach out to non-mental health professionals regarding their suicide risk.

This exploratory study aimed to examine whether suicide literacy was associated with non-mental health professionals ability to accurately recognize suicide risk, as this has not been

previously examined. It was hypothesized that those with higher levels of suicide literacy, a basic understanding of the different facets of suicidality (warning signs/symptoms, causes of suicidality, risk factors, and proper treatment and prevention; Batterham et al., 2013), would be more effective at accurately recognizing suicide risk than those with lower levels of suicide literacy. The results indicated that those with higher levels of suicide literacy were more effective at recognizing high levels of suicide risk but not other levels of suicide risk, including the absence of risk. This is a positive sign with regards to addressing the public health crisis that is suicide because the argument can be made that higher levels of suicide risk are more lethal than lower levels of suicide risk. While it is a positive sign that those with higher levels of suicide literacy were more effective at recognizing high suicide risk, it is concerning that that was not the case for moderate or low suicide risk, especially since moderate or even low suicide 
risk could lead to lethal consequences. This finding is particularly impactful as suicide literacy in association with ability to recognize suicide risk in others has not been previously examined. As this sample consisted primarily of individuals with no suicide prevention training, the findings may guide the development and implementation of suicide prevention trainings. For example, if high suicide literacy does not make individuals more accurate in recognizing moderate or low suicide risk, it may be pertinent to focus on interventions that go above simply increasing levels of suicide literacy. There are several potential reasons why a higher level of suicide literacy does not automatically mean that individuals will be more accurate at recognizing all levels suicide risk.

The results indicated that higher levels of suicide literacy are associated with a significant increase in an individual's ability to accurately recognize high suicide risk. This finding may be explained because it may be easier to translate one's knowledge about suicide to higher levels of suicide risk because high suicide risk vignette consists of more intense warning signs and less risk factors than the other risk categories. As mentioned earlier, risk factors refer to characteristics that make an individual more likely to be at risk for suicide but don't speak to an individual's immediate level of risk. On the other hand, warning signs refer to signs and symptoms that an individual is at immediate risk of suicide. It may be that non-mental health professionals have an easier time recognizing warning signs than they do recognizing risk factors. This explanation is supported by the fact that the mean score for accuracy on the highrisk vignette (which contained the more intense warning signs than the other risk categories) was significantly higher than any other category, meaning that participants were more accurate at responding to the high-risk vignette than any of the other vignettes. This may mean that it is easier for individuals to utilize their suicide literacy to accurately recognize suicide risk, when 
that risk pertains to warning signs rather than risk factors. In order to combat this potential discrepancy between warning signs and risk factors it would be prudent to incorporate risk factors of suicide more frequently with regards to the development and implementation of suicide prevention trainings.

Another reason that participants were more effective at accurately recognizing high suicide risk is that it may be easier for participants to recognize suicide risk in those with similar demographics. For example, the high-risk vignette was about a 19-year-old female college student and the majority of the participants were female (74\%), the vast majority were around the age of $19(91 \%)$, and all of the participants were current college students. It may be that if the participants identified more with the individuals in the vignette that more closely matched their demographics, in turn making it easier to identify the risk. While demographics are important to the research on suicide due to the fact that risk differs across demographics, no significant correlations with regards to demographics were discovered. This could be due to the aforementioned lack of variability in the sample. More vignettes for each risk category and a significantly more diverse sample would be needed to further examine whether personal identification with the vignettes increases accuracy with regards to suicide risk.

The study also aimed to examine whether LGBTQ individuals were more accurate in their assessment of suicide risk than non-LGBTQ individuals. LGBTQ individuals at are much higher risk for suicide attempts and death by suicide than their non-LGBTQ counterparts Grossman \& D’Augelli, 2007 \& Marshal et al., 2011). A plethora of studies have also linked suicide among the LGBTQ community has also been linked to elevated rates of bigoted physical or verbal abuse (D’Augelli, Pilkington, \& Hershberger, 2002; O’Shaughnessy et al., 2004; Russell \& Joyner, 2001). In order to begin to devise solutions to this crisis of suicidality among 
LGBTQ individuals, it is imperative to examine whether higher levels of suicide risk and increased exposure to suicide translate to an increased ability to recognize suicide risk in others among LGBTQ individuals. It was hypothesized that due to heightened level of suicide risk and community emphasis on suicide prevention (Grossman \& D'Augelli, 2007 and Marshal et al., 2011), LGBTQ individuals would be more accurate in their assessment of suicide risk than their non-LGBTQ counterparts. The results indicated that LGBTQ individuals were not more effective than non-LGBTQ individuals at accurately recognizing suicide risk in others. While LGBTQ individuals were not more accurate at recognizing suicide risk, they did demonstrate higher levels of suicide literacy. This finding is important because previous research has linked higher levels of suicide literacy to increased help-seeking behaviors (Batterham et al., 2013).

The higher level of suicide literacy among LGBTQ individuals may be attributed to the increased emphasis on suicide prevention within the LGBTQ community (Marshal et al., 2011), which likely led to exposure to information regarding suicide, which in turn led to increased suicide literacy. Due to the alarmingly high rates of suicide among the LGBTQ population, suicide prevention programs have made an effort to target LGBTQ populations and it may be due to this that LGBTQ individuals have a higher level of suicide literacy. It stands to reason that if one discovers that they are more at risk of dying in a certain way, they may be more encouraged to learning more about that potential risk.

This difference in suicide literacy could also be explained by how often LGBTQ individuals talk about suicide with family or friends. For example, those that identified as bisexual reported talking about suicide much more often than their non-LGBTQ counterparts. It is possible that talking about suicide more frequently has made LGBTQ individuals more suicide literate. This difference in the frequency that LGBTQ and non-LGBTQ individuals discuss 
suicide may be attributed to LGBTQ individuals recognizing that they are more at risk of suicide, thus seeking out conversation related to the topic. It is important to emphasize that this increased suicide literacy did not translate to increased accuracy at recognizing all types of suicide risk. That being said, it is also important to note that increased suicide literacy does translate to increased accuracy at recognizing high suicide risk, which is essential as high suicide risk may have lethal consequences.

\section{Limitations and Future Research}

The primary limitation of this study centers around the fact that suicide literacy and accurate recognition of suicide risk in others has not been previously examined in conjunction. While this study aims to explore a gap in the existing literature pertaining to suicide prevention, it also lacks a significant theoretical foundation. This can be addressed through further exploration in this area of study. This study also aimed to compare LGBTQ individuals and nonLGBTQ individuals but lacked adequate representation for certain members of the LGBTQ community. For example, very few gay men or transgender men and no transgender women participated in the study. The studies sample also, similar to much of the psychology research conducted on college students, was not representative of all genders and age groups. For example, the vast majority of participants were between the ages of 18-24. Cisgender women were also significantly overrepresented in the sample. These demographic limitations could be addressed by more active recruitment of LGBTQ individuals in future research.

Another limitation of the study was that only one mode (self-report) of data collection was utilized. Future research would benefit from utilizing a plethora of modes to analyze this topic including interviews or focus groups in addition to self-report measures. This mix-method approach would provide a more comprehensive and complete examination and understanding of 
the research questions than the purely quantitative approach this study utilized. Incorporating a qualitative aspect to this study would allow us to have a clearer understanding of the processes that occur when the average person is assessing suicide risk. This study could have also benefited from simply increasing the number of vignettes in order to establish more robust findings. For example, utilizing two or three vignettes per each risk category may yield more concrete results.

Future research on this topic would benefit from examining suicide literacy and accurate recognition of suicide risk utilizing a more experimental approach. For example, future research could focus on developing and examining the efficacy of interventions targeted at increasing individuals' ability to accurately recognize the various levels of suicide risk without simply focusing on interventions that aim to increase suicide literacy. These potential interventions could include more experientially-based activities like role-playing and practicing assessing suicidal individuals (with expert feedback available) through the use of vignettes.

\section{Implications}

These findings present several implications with regards to how best train non-mental health professionals to accurately recognize suicide risk. There exist many suicide prevention training programs that aim to train non-mental health professionals on recognizing suicide but the most widely disseminated by far is known as Question, Persuade, Refer or QPR. To date, this hour-long suicide prevention training has reached over 1,000,000 people all over the world (QPR Institute, 2017). The vast majority of suicide prevention trainings, QPR included, focus on teaching individuals about the facts, myths, warning signs, and risk factors of suicide (QPR Institute, 2014). In other words, these suicide prevention training programs focus on increasing individuals' suicide literacy. The results of this study indicate that this this method of suicide prevention training (increasing suicide literacy to increase accuracy recognizing suicide risk) is 
effective with regards to high suicide risk, it may not be the best approach with regards to moderate or low levels of suicide risk. While there is a significant amount of research that demonstrates the positive effects of QPR and similar evidence-based suicide prevention programs (Litteken \& Sale, 2018) it may be pertinent to include interventions that go beyond simply increasing suicide literacy. Further research would be required to ascertain which interventions would be effective at increasing recognition of moderate and low suicide risk.

The findings of this study indicate that suicide risk assessment is complex and nuanced. If suicide risk assessment simply consisted of understanding the facts of suicide, there would have been a significant association between suicide literacy and all of the levels of suicide risk but that was not the case. This finding implies that moderate and low levels of suicide risk may be more difficult to accurately assess. If that is in fact the case, complex and nuanced methods of training individuals to recognize the various levels of suicidality is required. It seems that the majority of current suicide prevention programs are focused at simply increasing the suicide literacy of those being trained but that may not be enough. Complex problems like suicide require complex solutions.

This study also found that certain groups (LGBTQ individuals) were more suicide literate than others (non-LGBTQ individuals). This is particularly important as accurate recognition of high suicide risk is positively associated with higher levels of suicide literacy. It would be informative to examine why these groups differ in their suicide literacy. One potential reason for this is that LGBTQ individuals had more exposure to suicidality in that they talked to family and friends about it more often their non-LGBTQ individuals. If talking more about suicidality does in fact increase literacy, then it is imperative that discussion of suicidality is increased in populations that have lower levels of suicide literacy. 
In conclusion suicide is a complex public health crisis. Suicide affects hundreds of thousands of individuals directly each year and thousands more indirectly (World Health Organization, 2013). This study's primary aim was to examine whether suicide literacy is associated with an increased ability to accurately recognize suicide risk in others. According to the results of this study high levels of suicide literacy are in fact associated with an increased ability to accurately recognize high levels of suicide risk in others. This finding may help inform those developing and implementing suicide prevention programs. For example, suicide prevention efforts may benefit from focusing on increasing individuals suicide literacy so they can be more effective at recognizing high levels of suicide risk. Furthermore, this finding may encourage the development of methods targeted at improving recognition of moderate or low levels of suicide risk, as an increase in suicide literacy doesn't seem to significantly improve recognition of lower levels of suicide risk. Lastly, it is pertinent that further research is conducted on suicide risk assessment among non-mental health professionals, as they are more than likely to interact with someone at risk of suicide in their lifetimes. 


\section{REFERENCES}

Barker, G., Olukoya, A., \& Aggleton, P. (2005). Young people, social support and help-seeking. International Journal of Adolescent Medicine and Health, 17(4). http://doi:10.1515/ijamh.2005.17.4.315

Barzilay, S., \& Apter, A. (2014). Psychological models of suicide. Archives of Suicide Research,18(4), 295-312. http://doi:10.1080/13811118.2013.824825

Batterham, P. J., Calear, A. L., \& Christensen, H. (2013). Correlates of suicide stigma and suicide literacy in the community. Suicide and Life-Threatening Behavior, 43(4), 406417. http://doi:10.1111/s1tb.12026

Beautrais, A. L. (2002). A Case control study of suicide and attempted suicide in older adults. Suicide and Life-Threatening Behavior, 32(1), 1-9. http://doi:10.1521/suli.32.1.1.22184

Berman, A. L., \& Silverman, M. M. (2013). Suicide risk assessment and risk formulation part II: suicide risk formulation and the determination of levels of risk. Suicide and LifeThreatening Behavior, 44(4), 432-443. http://doi:10.1111/sltb.12067

Bostwick, J. M., \& Pankratz, V. S. (2000). Affective disorders and suicide risk: a reexamination. American Journal of Psychiatry, 157(12), 1925-1932. http://doi: 10.1176/appi.ajp.157.12.1925

Bryan, C. J., \& Rudd, M. D. (2006). Advances in the assessment of suicide risk. Journal of Clinical Psychology, 62, 185-200. http://dx.doi.org/10 .1002/jclp.20222

Bryan, C. J. (2011). The clinical utility of a brief measure of perceived burdensomeness and thwarted belongingness for the detection of suicidal military personnel. Journal of Clinical Psychology,67(10), 981-992. doi:10.1002/jclp.20726 
Busch, K. A., Fawcett, J., \& Jacobs, D. G. (2003). Clinical correlates of inpatient suicide. The Journal of Clinical Psychiatry, 64(1), 14-19. http://doi:10.4088/jcp.v64n0105

Calear, A.L., Batterham, P., \& Christensen, H. (2014). Predictors of help-seeking for suicidal ideation in the community: Risks and opportunities for public suicide prevention campaigns. Psychiatry Research, 219(3), 525-530 http://dx.doi.org/10.1016/j. psychres.2014.06.027.

Cavanagh, J. T., Carson, A. J., Sharpe, M., \& Lawrie, S. M. (2003). Psychological autopsy studies of suicide: a systematic review. Psychological Medicine, 33(3), 395-405. http://doi: 10.1017/S0033291702006943

Christiansen, E., \& Jensen, B. F. (2007). Risk of repetition of suicide attempt, suicide or all deaths after an episode of attempted suicide: A register-based survival analysis. Australian \& New Zealand Journal of Psychiatry, 41(3), 257-265. http://doi:10.1080/00048670601172749

Chu, C., Hom, M. A., Stanley, I. H., Gai, A. R., Nock, M. K., Gutierrez, P. M., \& Joiner, T. E. (2018). Non-suicidal self-injury and suicidal thoughts and behaviors: A study of the explanatory roles of the interpersonal theory variables among military service members and veterans. Journal of consulting and clinical psychology, 86(1), 56. http://dx.doi.org/10.1037/ccp0000262

Conwell, Y. (1994). Suicide and terminal illness: Lessons from the HIV pandemic. Crisis: The Journal of Crisis Intervention and Suicide Prevention, 15(2), 57-58. Retrieved from http://libproxy.lib.ilstu.edu/login?url=https://search.ebscohost.com/login.aspx?direct=true $\& \mathrm{db}=$ psyh $\& \mathrm{AN}=1995-05755-001 \&$ site $=$ ehost-live $\&$ scope $=$ site 
D’Augelli, A. R., Pilkington, N. W., \& Hershberger, S. L. (2002). Incidence and mental health impact of sexual orientation victimization of lesbian, gay, and bisexual youths in high school. School Psychology Quarterly, 17(2), 148-167. http://dx.doi.org/10.1521/scpq.17.2.148.20854

Domènech-Abella, J., Lara, E., Rubio-Valera, M., Olaya, B., Moneta, M., Rico-Uribe, L., ... Haro, J. M. (2017). Loneliness and depression in the elderly: the role of social network. Social Psychiatry \& Psychiatric Epidemiology, 52(4), 381-390. https://doi.org/10.1007/s00127-017-1339-3.

Domino, G. (1990). Popular misconceptions about suicide: How popular are they? OMEGA Journal of Death and Dying, 21(3), 167-175. http://doi:10.2190/c1d7-av2p-t5lu-j91v

Duberstein, P. R., Conwell, Y., Conner, K. R., Eberly, S., \& Caine, E. D. (2004). Suicide at 50 years of age and older: perceived physical illness, family discord and financial strain. Psychological Medicine, 34(1), 137-146. https://doi.org/10.1017/S0033291703008584

Duberstein, P., \& Witte, T. K. (2009). Suicide risk in personality disorders: An argument for a public health perspective. In P. M. Kleespies (Ed.), Behavioral emergencies: An evidence-based resource for evaluating and managing risk of suicide, violence, and victimization. (pp. 257-286). Washington, DC: American Psychological Association. https://doi.org/10.1037/11865-012

Eaddy, M., Zullo, L., Horton, S. E., Hughes, J. L., Kennard, B., Diederich, A., ... \& Stewart, S. M. (2018). A Theory-driven investigation of the association between emotion dysregulation and suicide risk in a clinical adolescent sample. Suicide and LifeThreatening Behavior. https://doi.org/10.1111/sltb.12472 
Farrer, Louise, Liana Leach, Kathleen M. Griffiths, Helen Christensen, and Anthony F. Jorm. "Age differences in mental health literacy." BMC Public Health 8, no. 1 (2008): 125. https://doi.org/10.1186/1471-2458-8-125

Ferguson, M. S., Reis, J. A., Rabbetts, L., Ashby, H.-J., Bayes, M., McCracken, T., . . Procter, N. G. (2018). The effectiveness of suicide prevention education programs for nurses: A systematic review. Crisis: The Journal of Crisis Intervention and Suicide Prevention, 39(2), 96-109. http://dx.doi.org/10.1027/0227-5910/a000479

Fisher, L. J., \& Goldney, R. D. (2003). Differences in community mental health literacy in older and younger Australians. International journal of geriatric psychiatry, 18(1), 33-40. https://doi.org/10.1002/gps.769

Freud, S. (1957). Mourning and melancholia. In The Standard Edition of the Complete Psychological Works of Sigmund Freud, Volume XIV (1914-1916): On the History of the Psycho-Analytic Movement, Papers on Metapsychology and Other Works (pp. 237-258).

Griffiths, K. M., Christensen, H., \& Jorm, A. F. (2008). Predictors of depression stigma. BMC psychiatry, 8(1), 25. https://doi.org/10.1186/1471-244X-8-25

Goodwin, R. D., Marusic, A., \& Hoven, C. W. (2003). Suicide attempts in the United States: the role of physical illness. Social science \& medicine, 56(8), 1783-1788. https://doi.org/10.1016/S0277-9536(02)00174-0

Grossman, A. H., \& D'augelli, A. R. (2007). Transgender youth and life-threatening behaviors. Suicide and life-threatening behavior, 37(5), 527-537. https://doi.org/ 10.1521/suli.2007.37.5.527 
Haas, A. P., \& Lane, A. (2015). Collecting sexual orientation and gender identity data in suicide and other violent deaths: A step towards identifying and addressing LGBT mortality disparities. LGBT Health, 2(1), 84-87. https://doi.org/10.1089/lgbt.2014.0083

Harris, E. C., \& Barraclough, B. (1997). Suicide as an outcome for mental disorders: a metaanalysis. The British journal of psychiatry, 170(3), 205-228. https://doi.org/10.1192/bjp.170.3.205

Hawton K., \& Van Heeringen, C. (n.d.). The International Handbook on Suicide and Attempted Suicide. John Wiley \& Sons, Chichester, 2000, 755 p.

Hawton, K., Zahl, D., \& Weatherall, R. (2003). Suicide following deliberate self-harm: longterm follow-up of patients who presented to a general hospital. The British Journal of Psychiatry, 182(6), 537-542. https://doi.org/10.1192/bjp.182.6.537

Heerde, J. A., \& Hemphill, S. A. (2017). Examination of associations between informal helpseeking behavior, social support, and adolescent psychosocial outcomes: A metaanalysis. Developmental Review. https://doi.org/10.1016/j.dr.2017.10.001

Hor, K., \& Taylor, M. (2010). Suicide and schizophrenia: a systematic review of rates and risk factors. Journal of psychopharmacology, 24(4_suppl), 81-90. https://doi.org/10.1177/1359786810385490

Joiner, T. (2005). Why people die by suicide. Cambridge, MA, US: Harvard University Press. Joiner, T. E., Pettit, J. W., Walker, R. L., Voelz, Z. R., Cruz, J., Rudd, M. D., \& Lester, D. (2002). Perceived burdensomeness and suicidality: Two studies on the suicide notes of those attempting and those completing suicide. Journal of Social and Clinical Psychology, 21(5), 531-545. https://doi.org/10.1521/jscp.21.5.531.22624 
Joiner Jr, T. E., \& Van Orden, K. A. (2008). The interpersonal-psychological theory of suicidal behavior indicates specific and crucial psychotherapeutic targets. International Journal of Cognitive Therapy, 1(1), 80-89. https://doi.org/10.1521/ijct.2008.1.1.80

Jorm, A. F. (2012). Mental health literacy: Empowering the community to take action for better mental health. American Psychologist, 67(3), 231. http://doi:10.1037/a0025957

Jorm, A. F. (2000). Mental health literacy: Public knowledge and beliefs about mental disorders. The British Journal of Psychiatry, 177(5), 396-401. https://doi.org/10.1192/bjp.177.5.396

Jorm, A. F., Barney, L. J., Christensen, H., Highet, N. J., Kelly, C. M., \& Kitchener, B. A. (2006). Research on mental health literacy: what we know and what we still need to know. Australian \& New Zealand Journal of Psychiatry, 40(1), 3-5. https://doi.org/10.1111/j.1440-1614.2006.01734.x

Jorm, A. F., Christensen, H., \& Griffiths, K. M. (2006). The public's ability to recognize mental disorders and their beliefs about treatment: changes in Australia over 8 years. Australian \& New Zealand Journal of Psychiatry, 40(1), 36-41. https://doi.org/10.1111/j.14401614.2006.01738.x

Jorm, A. F., Korten, A. E., Jacomb, P. A., Christensen, H., Rodgers, B., \& Pollitt, P. (1997). "Mental health literacy": A survey of the public's ability to recognize mental disorders and their beliefs about the effectiveness of treatment. Medical Journal of Australia, 166, 5. Retrieved from http://libproxy.lib.ilstu.edu/login?url=https://search.ebscohost.com/login.aspx?direct=true $\& \mathrm{db}=$ psyh \&AN=2014-48769-001\&site=ehost-live \&scope $=$ site 
Kemp, J., \& Bossarte, R. (2013). Suicide data report: 2012. Washington, DC: Department of Veterans Affairs, Mental Health Services, Suicide Prevention Program.

King, C. A., \& Merchant, C. R. (2008). Social and interpersonal factors relating to adolescent suicidality: A review of the literature. Archives of Suicide Research, 12(3), 181-196. https://doi.org/10.1080/13811110802101203

Kitchener, B. A., \& Jorm, A. F. (2002). Mental health first aid training for the public: Evaluation of effects on knowledge, attitudes and helping behavior. BMC Psychiatry, 2. https://doi:10.1186/1471-244X-2-10

Lees, J., \& Stimpson, Q. (2002). A psychodynamic approach to suicide: a critical and selective review. British Journal of Guidance \& Counselling, 30(4), 373-382. https://doi.org/10.1080/0306988021000025592

Litteken, C., \& Sale, E. (2018). Long-term effectiveness of the question, persuade, refer (QPR) suicide prevention gatekeeper training program: lessons from Missouri. Community mental health journal, 54(3), 282-292. https://doi.org/10.1007/s10597-017-0158-z

Mandrusiak, M., Rudd, M. D., Joiner Jr, T. E., Berman, A. L., Van Orden, K. A., \& Witte, T. (2006). Warning signs for suicide on the internet: A descriptive study. Suicide and LifeThreatening Behavior, 36(3), 263-271. https://doi.org/10.1521/suli.2006.36.3.263

Marshal, M. P., Dietz, L. J., Friedman, M. S., Stall, R., Smith, H. A., McGinley, J., ... Brent, D. A. (2011). Suicidality and depression disparities between sexual minority and heterosexual youth: A meta-analytic review. Journal of Adolescent Health, 49(2), 115123. https://doi.org/10.1016/j.jadohealth.2011.02.005

Menninger, K. A. (1938). Man against himself. New York: Harcourt, Brace. 
Nelson, F. L. (1987). Evaluation of a youth suicide prevention school program. Adolescence, 22(88), 813-825. Retrieved from http://libproxy.lib.ilstu.edu/login?url=https://search.ebscohost.com/login.aspx?direct=true $\& \mathrm{db}=$ psyh \&AN=1988-15460-001\&site=ehost-live \&scope $=$ site

O'Mahony, S., Goulet, J., Kornblith, A., Abbatiello, G., Clarke, B., Kless-Siegel, S., ... \& Payne, R. (2005). Desire for hastened death, cancer pain and depression: report of a longitudinal observational study. Journal of Pain and Symptom Management, 29(5), 446-457. https://doi.org/10.1016/j.jpainsymman.2004.08.010

O’Shaughnessy, M., Russell, S. Heck, K., Calhoun, C. \& Laub, C. (2004). Safe place to learn: Consequences of harassment based on actual or perceived sexual orientation and gender non-conformity and steps for making schools safer. San Francisco, CA: California Safe Schools Coalition \& 4-H Center for Youth Development, University of California, Davis.

Owens, D., Horrocks, J., \& House, A. (2002). Fatal and non-fatal repetition of self-harm: systematic review. The British Journal of Psychiatry, 181(3), 193-199. https://doi.org/10.1192/bjp.181.3.193

Palmer, B. A., Pankratz, V. S., \& Bostwick, J. M. (2005). The lifetime risk of suicide in schizophrenia: a reexamination. Archives of general psychiatry, 62(3), 247-253. http://doi:10.1001/archpsyc.62.3.247

QPR Institute. (2014). QPR (Question, Persuade, Refer). Spokane, WA: QPR Institute. Retrieved from http://www.qprinstitute.com/

QPR Institute. (2017). Available from http://www.qprinstitute.com/. Accessed 6 June 2017. 
Rickwood, D., \& Thomas, K. (2012). Conceptual measurement framework for help-seeking for mental health problems. Psychology Research and Behavior Management, 5, 173. http://doi: $10.2147 /$ PRBM.S38707

Rudd, M. D., Berman, A. L., Joiner Jr, T. E., Nock, M. K., Silverman, M. M., Mandrusiak, M., ... \& Witte, T. (2006). Warning signs for suicide: Theory, research, and clinical applications. Suicide and Life-Threatening Behavior, 36(3), 255-262. https://doi.org/10.1521/suli.2006.36.3.255

Russell, S. T., \& Joyner, K. (2001). Adolescent sexual orientation and suicide risk: Evidence from a national study. American Journal of Public Health, 91, 1276-1281. https://doi.org/10.2105/AJPH.91.8.1276

Schurtz, D. R., Cerel, J., \& Rodgers, P. (2010). Myths and facts about suicide from individuals involved in suicide prevention. Suicide and Life-Threatening Behavior, 40(4), 346-352. https://doi.org/10.1521/suli.2010.40.4.346

Shneidman, E. S. (1993). Suicide as psychache; A clinical approach to self-destructive behavior. Lanham, MD: Jason Aronson. Retrieved from http://libproxy.lib.ilstu.edu/login?url=https://search.ebscohost.com/login.aspx?direct=true $\& \mathrm{db}=$ psyh \&AN=1993-98267-000\&site=ehost-live \&scope=site

Shumaker, S. A., \& Brownell, A. (1984). Toward a theory of social support: Closing conceptual gaps. Journal of Social Issues, 40(4), 11-36. Retrieved from http://libproxy.lib.ilstu.edu/login?url=https://search.ebscohost.com/login.aspx?direct=true $\& \mathrm{db}=$ sih $\& \mathrm{AN}=16410790 \&$ site $=$ ehost-live $\&$ scope $=$ site 
Silverman, M. M., \& Berman, A. L. (2014). Suicide risk assessment and risk formulation part I: A focus on suicide ideation in assessing suicide risk. Suicide and Life-Threatening Behavior, 44(4), 420-431. https://doi.org/10.1111/sltb.12065

Spino, E., Kameg, K. M., Cline, T. W., Terhorst, L., \& Mitchell, A. M. (2016). Impact of social support on symptoms of depression and loneliness in survivors bereaved by suicide. Archives of Psychiatric Nursing, 30(5), 602-606. https://doi.org/10.1016/j.apnu.2016.02.001

Suicide Prevention Toolkit. (2011). PsycEXTRA Dataset.

Van Orden, K. A., Witte, T. K., James, L. M., Castro, Y., Gordon, K. H., Braithwaite, S. R., . . Joiner, T. E., Jr. (2008). Suicidal ideation in college students varies across semesters: The mediating role of belongingness. Suicide and Life-Threatening Behavior, 38, 427- 435. http://doi: 10.1521/suli.2008.38.4.427

Van Orden, K. A., Witte, T. K., Cukrowicz, K. C., Braithwaite, S. R., Selby, E. A., \& Joiner, T. E., Jr. (2010). The interpersonal theory of suicide. Psychological Review, 117(2), 575600. https://doi.org/10.1037/a0018697.

Whitlock, F. (1986). Suicide and physical illness. In A. Roy (Ed.), Suicide (pp. 151-170). Baltimore, MD: Williams and Wilkins.

WISQARS (Web-Based Injury Statistics Query and Reporting System). (2011). Choice Reviews Online, 48(08). http://doi:10.5860/choice.48-4227 


\section{APPENDIX A: DEMOGRAPHIC SURVEY}

- Q1 How old are you?
$\circ 18$
○ 19
○ 20
○ 21
○ 22
$\circ 23$
$\circ 24$
$\circ 25+$
- Prefer not to answer

- Q2 What year of school are you in?
$\circ$ First-year
○ Second-year
$\bigcirc$ Third-year
Fourth-year
$\circ$ Other

- Q3 What gender do you identify with?
- Cisgender Man
○ Cisgender Woman
- Transgender Man
- Transgender Woman
○ Non-Binary 
O Other

- Q4 What sexual orientation do you identify with?
○ Straight
○ Gay
○ Lesbian
○ Bisexual
o Other

- Q5 What is your ethnicity?
○ White
○ Black
○ Latino
○ Hispanic
○ East Asian
- South Asian
○ Middle Eastern
- Native American
○ Hawaiian/Pacific Islander
○ Multi-race
○ Other

- Q6 Have you received training on suicide prevention?
○ Yes
○ No

- Q7 How often do family and friends talk to you about suicide? 
○ Never

○ Rarely

○ Sometimes

○ Often

- Almost Always

- Q8 How often do family and friends talk to you about experiencing suicidal thoughts?

○ Never

○ Rarely

○ Sometimes

○ Often

○ Almost Always

- Q9 How often have your family and friends talked to you about attempting suicide?

o Never

o Rarely

o Sometimes

o Often

o Almost Always 


\section{APPENDIX B: SUICIDE RISK VIGNETTES}

Maria Vignette (High-Risk): Maria is a 19-year-old college student who, until recently, was heavily involved in student government, extracurriculars, and organizing campus events. She often feels overwhelmed by the pressure of all she's doing. As a result of feeling so overwhelmed, her previously stellar grades have started to steadily decline. In an attempt to catch up, she decided to buy Adderall from one of her roommates. Instead of helping her stay focused, the Adderall only caused her to feel keyed-up and irritable all the time. In addition to that, her longtime boyfriend broke up with her because he felt she wasn't making enough time for him. She doesn't believe that she'll ever have such an intimate relationship again. Maria has also started to withdraw from her friends, started skipping her classes and has stopped attending her extracurricular activities. One of her professors noticed her absences and asked her to come to his office hours. After meeting with her, he suggested that she go to the student counseling to get help. Maria agreed to go but admitted that she didn't think it would help, since she probably wouldn't be around much longer.

Curtis Vignette (Moderate Risk): Curtis is a 68-year-old man who recently decided to move into a retirement home. Even though Curtis fiercely values his independence, he has had a series of minor accidents that have forced him to move into a retirement home with assisted-living. Curtis lost his wife of 40 years a few months ago and has been fairly isolated ever since. He has been retired from his job for nearly a decade and spends most of his day reading or watching television. The staff of the retirement home reports that Curtis has seemed depressed and withdrawn ever since moving in. Curtis has struggled with depression throughout his life. He used to take antidepressants regularly and has only stopped recently. When asked if he would have any visitors for the holidays, Curtis replied with "No. My wife and I didn't have any kids. 
And now she's gone". When Curtis first moved into the retirement home, he made a few friends and didn't struggle with interacting with others but that has recently changed. Staff members have reported that he stopped socializing with other residents and when they try to socialize with him, he often reacts in a hostile manner.

Sam Vignette (Low Risk): Sam is 35-year-old father of two young children. He works in a midlevel position at an accounting firm. He plans on working his way up to partner at the firm one day. He is a dedicated member of his church and volunteers at a soup kitchen every weekend. He recently lost one of his older brothers in a car accident. This has affected him deeply because he shares a very close relationship with his siblings. His wife is a bit worried about him because she remembered him mentioning that one of his cousins committed suicide decades ago. His wife suggested that he take some time off from work to deal with the sadness he is feeling over his brother's sudden death. He has found it difficult to accept support from his congregation because they often tell him that his brother's death was part of "God's plan" and he has a hard time wrapping his head around that. In order to help him cope with the situation, he has decided to join a grief/loss support group. Thanks to the support group, Sam has started to feel hopeful that he'll be able to get passed this tragedy.

Ashley Vignette (No Risk): Ashley is a 26-year-old woman who works as a banker. She is engaged to her girlfriend of 5 years. Her job is incredibly stressful but also really rewarding for her. She has a tight knit group of friends that she regularly sees. Ashley is also very close with her parents and tries to visit them at least once a month. At first, her parents struggled with accepting her when she came out to them, but they have been nothing but supportive after the initial shock. Outside of work, Ashley is really involved in volunteering at a local group home for foster kids. Ashley recently found out that, due to budget cuts, the foster home will be 
closing. Ashley was devastated by the news because she really connected with the foster kids she was working with. Her fiancée noticed her distress at the situation and suggest that she and Ashley look into becoming foster parents once they get married. While she was still really broken up about the fate of the foster home, she was also elated by the idea of becoming a foster parent. Ashley plans on hiring a foster care lawyer to get the processes started. 


\section{APPENDIX C: LITERACY OF SUICIDE SCALE}

True

False

Don't know

1. Nothing can be done to stop people from making the attempt once they have made up their minds to kill themselves

2. If assessed by a psychiatrist, everyone who suicides would be diagnosed as depressed

3. Seeing a psychiatrist or psychologist can help prevent someone from suicide

4. Most people who suicide are psychotic

5. Only experts can help people who want to suicide

6. There is a strong relationship between alcoholism and suicide

7. People who talk about suicide rarely kill themselves

8. People who want to attempt suicide can change their mind quickly

9. Talking about suicide always increases the risk of suicide

10. A person who has made a past suicide attempt is more likely to attempt suicide again than someone who has never attempted

11. Media coverage of suicide will inevitably encourage other people to attempt suicide

12. Not all people who attempt suicide plan their attempt in advance

13. People who have thoughts about suicide should not tell others about it

14. Very few people have thoughts about suicide

15. People who are anxious or agitated have a higher risk of suicide

16. Most people who suicide are younger than 30

\section{Men are more likely to suicide than women}

18. People with relationship problems or financial problems have a higher risk of suicide

19. Most people who suicide don't make future plans 


\section{True

20. If you asked someone directly " Do you feel like killing yourself?" it will likely lead that person to make a suicide attempt

21. A suicidal person will always be suicidal and entertain thoughts of suicide

22. A person who suicides is mentally ill

23. A time of high suicide risk in depression is at the time when the person begins to improve

24. Motives and causes of suicide are readily established

25. Most people who attempt suicide fail to kill themselves

26. Those who attempt suicide do so only to manipulate others and attract attention to themselves 